\title{
Two-phase operational maps, pressure drop, and heat transfer for flow boiling of R236fa in a micro-pin fins evaporator
}

\author{
C. Falsetti*, H. Jafarpoorchekab, M. Magnini, N. Borhani, J. R. Thome \\ Laboratory of Heat and Mass Transfer (LTCM), Ecole Polytechnique Fédérale de
} Lausanne (EPFL), EPFL-STI-IGM-LTCM, Station 9, CH-1015 Lausanne, Switzerland

\section{Abstract}

Cooling the new generation of 3D high power electronic chips is one of the leading challenges in microelectronics, as it is a key to achieve high computational performance at lower cooling system power consumption, thus reducing the operating cost. Two-phase flow boiling in two micro-pin fins heat sinks is studied here for this cooling process. Each micro-evaporator has a heated area of $1 \mathrm{~cm}^{2}$ and contains 66 rows of cylindrical micro-pin fins with an in-line configuration and diameter, height and pitch of respectively $50 \mu \mathrm{m}, 100 \mu \mathrm{m}$ and $91.7 \mu \mathrm{m}$. The fluid tested is refrigerant R236fa. Channel entrances with and without inlet restrictions are tested in order to evaluate their relative effect on the stability of the flow. The inlet restrictions consist of an extra row of micro-pin fins with a larger diameter of $100 \mu \mathrm{m}$ placed at the inlet of the heated area. The present study investigates operational stable and unstable flow regimes, pressure drop and heat transfer performance

\footnotetext{
*Corresponding author. Tel.: +41 (0)21 6935442.

Email addresses: chiara.falsetti@epfl.ch (C. Falsetti), hamide.jafarpoor@gmail.com (H. Jafarpoorchekab), mirco.magnini@epfl.ch (M. Magnini), navid.borhani@epfl.ch (N. Borhani), john.thome@epfl.ch (J. R. Thome) 
for the two micro-evaporators (one with and one without inlet restrictions) by coupling high speed visualization of the micro-pin fins flow area with fine resolution infrared temperature measurements of the micro-evaporator base, which yields a 2D map of local heat transfer coefficients of the whole heated area. Working conditions tested have mass flux varying from $500 \mathrm{~kg} \mathrm{~m}^{-2} \mathrm{~s}^{-1}$ to $2500 \mathrm{~kg} \mathrm{~m}^{-2} \mathrm{~s}^{-1}$, heat flux ranging from $20 \mathrm{~W} \mathrm{~cm}^{-2}$ to $48 \mathrm{~W} \mathrm{~cm}^{-2}$, and a constant outlet saturation temperature of $30.5^{\circ} \mathrm{C}$. In agreement with previous studies for multi-microchannel evaporators, it is here observed that inlet restrictions extend the map of stable operational regimes, in particular toward lower values of the mass flux, without any appreciable increase of the pressure drop. Unlike evaporation through parallel microchannels, the heat transfer coefficient trends and magnitudes vary dramatically with the flow conditions (mass flux and heat flux), thus suggesting that micro-pin fins have a strong impact on the two-phase flow pattern development, in particular delaying the transition to annular flow.

Keywords: Two-phase flow, Flow boiling, Micro-pin fins, High speed visualization, Infrared camera measurements.

\section{Introduction}

In the multicore era in which multiple CPU cores are stacked on the same chip in order to reduce the power input and the communication latency, newer and smarter integrated circuit (IC) architectures are required to have more compact solutions and to decrease the time for a signal to propagate between transistors, which is considered to be the main limit of the new technology. During the last decade, microelectronic industries are 
moving towards vertical chip integration which leads to many advantages, such as reduced supply voltage, reduction of size and improved computing performance at lower power consumption and costs [1]. Conventional cooling systems, such as backside air-cooling, are only capable of cooling single layer logical dies [2], while single phase and two-phase based interlayer cooling techniques seem to have the capability of meeting the 3D-IC demands of thermal dissipation. Single phase water cooling systems represent a potential solution due to their low working pressure and water's high thermal capacity, but they present two main disadvantages: (i) non-uniform distribution of temperature on the heated area and thus the chip, and (ii) risk of damage the electronics in case of leakage [3]. Two-phase flow of a dielectric coolant provides higher heat transfer rate thanks to the latent heat absorbed by the vaporization of the liquid. Since the heat transfer coefficient is very high, a two-phase micro heat sink can be very compact in size and it requires smaller flow rates compared to single phase cooling. The most widely studied geometry for two-phase flow cooling to date consists of parallel multimicrochannels, and the related literature is vast. For this, numerous fluids and channel dimensions have been tested and prediction methods proposed $[4,5,6,7,8,9,10]$.

Micro-pin fins represent a possible alternative to parallel microchannels and are the heat sink geometry studied in the present work. The pin fins act as a natural housing for the Through Silicon Vias (TSV) between the chip layers, also enhancing mixing and promoting uniform flow distribution across the flow region [11]. However, the thermal and fluid dynamic analysis of micro-pin fins evaporators have received less attention compared to parallel 
microchannels and the available literature is still rather limited.

Below, the available literature is reviewed in detail, first for single phase working fluid and then for two-phase flow, in order to emphasize the data reduction technique utilized and the results obtained in terms of flow patterns and heat removal performances.

Brunschwiler et al. [12] studied water in single phase flow with a doublesided heated test section for different geometries of micro-pin fins etched in silicon, including in-line and staggered configurations, of round and droplike shapes and pitches ranging from $50 \mu \mathrm{m}$ to $200 \mu \mathrm{m}$, at Reynolds numbers smaller than 1000. The surface temperature was evaluated by an infrared camera, but no flow visualization was possible. The fluid temperature was assumed to vary linearly between the inlet and outlet sections, where these temperatures were measured by means of T-type thermocouples. The microevaporator dissipated up to above $200 \mathrm{~W} \mathrm{~cm}^{-2}$ for pitches larger than $50 \mu \mathrm{m}$ with a pressure drop of $0.6 \cdot 10^{5} \mathrm{~Pa}$.

In the work of Renfer et al. [11], the flow thermal map was visualized via a micron-resolution laser-induced fluorescence $(\mu \mathrm{LIF})$ technique, which was useful to see the start of vortex shedding downstream of each micro-pin fins. The micro-pin fins were etched into silicon with deep reactive ion etching (DRIE). At low Reynolds numbers they found a laminar pre-transition regime in which there were recirculation zones behind the micro-pin fins and channel-like flow between the pin fins in the array. At larger Reynolds numbers, transversal fluctuations helped to mix the flow between channels and enhanced heat transfer. These flow transitions enhanced the heat transfer performance by up to $230 \%$ and reduced the chip temperature non-uniformity. 
$\mathrm{Qu}$ et al. [13] performed several experimental studies using deionized water as the working fluid in single phase flow, in an array of square staggered micro-pin fins. The micro-pin fins were made by copper, machined using a microend mill. They compared their measurements of Nusselt number and friction factor with selected correlations from the open literature, and proposed a new correlation for the heat transfer coefficient that best fit their data. In their data reduction, they computed the micro-pin fin surface temperatures by means of a 1D heat conduction model from a thermocouple measurement at the micro-evaporator base (similarly to what was done by Krishnamurthy and Peles [14]), while the saturation temperature was obtained from the local pressure, assumed to decrease linearly in the boiling region.

Recently, Mita and Qu investigated the pressure drop in single [15] and twophase [16] flow across a staggered array of circular micro-pin fins of $18 \mu \mathrm{m}$ diameter, $683 \mu \mathrm{m}$ height and $399 \mu \mathrm{m}$ pitch in both directions, using water as the cooling fluid. The test section was fabricated as a previous work of the same author [13]. In the single phase part, they showed that the existing correlations for micro-pin fin arrays as well as tube banks for friction factor were not able to predict their experimental data.

Kosar and Peles [17] studied single phase R-123 flow and inception of boiling in an array of staggered micro-pin fins of height $243 \mu \mathrm{m}$, diameter of $99.5 \mu \mathrm{m}$ and a pitch size equal to $150 \mu \mathrm{m}$, within a range of heat fluxes from $3.5 \mathrm{~W} \mathrm{~cm}^{-2}$ to $65.5 \mathrm{~W} \mathrm{~cm}^{-2}$ and Reynolds number from 134 to 314. The device was fabricated by processing a silicon wafer using microfabrication techniques. Kosar and Peles [18] then performed flow boiling experi- 
ments on arrays of hydrofoil shaped pin fins with R-123, heat fluxes ranging from $19 \mathrm{~W} \mathrm{~cm}^{-2}$ to $312 \mathrm{~W} \mathrm{~cm}^{-2}$, and mass fluxes from $976 \mathrm{~kg} \mathrm{~m}^{-2} \mathrm{~s}^{-1}$ to $2349 \mathrm{~kg} \mathrm{~m}^{-2} \mathrm{~s}^{-1}$. In both studies, the average surface temperature was estimated with a 1-D steady state heat conduction starting from the heater temperature, which was found using an electrical resistance-temperature calibration curve, while the saturation temperature was calculated from a linear pressure profile assumed between the inlet and outlet measured pressure values. They showed that these average heat transfer coefficients were strongly dependent on mass velocity and vapor quality, increasing with heat flux until the critical heat flux condition was reached. They observed three flow patterns that they classified as bubbly, wavy and spray-annular flows depending on the Boiling number.

Krishnamurthy and Peles [14] also conducted flow boiling experiments with an array of circular, staggered micro-pin fins using water as the coolant for heat fluxes from $20 \mathrm{~W} \mathrm{~cm}^{-2}$ to $350 \mathrm{~W} \mathrm{~cm}^{-2}$ and mass fluxes from $346 \mathrm{~kg} \mathrm{~m}^{-2} \mathrm{~s}^{-1}$ to $794 \mathrm{~kg} \mathrm{~m}^{-2} \mathrm{~s}^{-1}$. The evaporator surface temperature was estimated starting from the base temperature by utilizing a 1D heat conduction model, while the saturation temperature was obtained using a pressure profile reconstructed by means of a modified version of the Chisholm model [19]. They showed that the two-phase heat transfer coefficient was independent of heat flux, such that convective boiling was identified to be the dominant heat transfer mechanism. In a subsequent work [20], they examined flow boiling of HFE-7000 in $222 \mu \mathrm{m}$ hydraulic diameter parallel channels, each containing a single row of 24 in-line pin fins of $100 \mu \mathrm{m}$ of diameter. The mass fluxes ranged from $350 \mathrm{~kg} \mathrm{~m}^{-2} \mathrm{~s}^{-1}$ to $827 \mathrm{~kg} \mathrm{~m}^{-2} \mathrm{~s}^{-1}$ and wall heat fluxes ranged 
from $10 \mathrm{~W} \mathrm{~cm}^{-2}$ to $110 \mathrm{~W} \mathrm{~cm}^{-2}$. The heat transfer coefficients were found to be higher with this geometry configuration than with the plain microchannels and the flow visualization confirmed the presence of different patterns along the channel length, i.e. isolated bubbles, interacting bubbles and annular flow.

As mentioned above, Mita and Qu [16] investigated two-phase pressure drops, showing that it was strongly dependent on vapor quality and that the Lockart and Martinelli prediction procedure could still be applied to evaluate the pressure drop [21].

Isaacs et al. [22] performed experiments with R245fa in an array of staggered micro-pin fins with a $150 \mu \mathrm{m}$ diameter, $200 \mu \mathrm{m}$ height and $225 \mu \mathrm{m}$ pitch. They evaluated average values of the heat transfer coefficient for multiple heat loads (from $20 \mathrm{~W} \mathrm{~cm}^{-2}$ to $35 \mathrm{~W} \mathrm{~cm}^{-2}$ ) and flow rates $\left(20 \mathrm{ml} \mathrm{min}^{-1}\right.$ - $40 \mathrm{ml} \mathrm{min}^{-1}$ ) in two-phase flow. The fluid temperature was considered constant over the fin array, and estimated as the saturation temperature corresponding to an average pressure value between inlet and outlet measurements. In their tests, the average heat transfer coefficient decreased with increasing heat flux and vapor quality. Flow visualization suggested that the reduction of the heat transfer coefficient could be explained by the development of a larger partial and intermittent dry-out zone near the evaporator exit.

The micro-pin fin literature review above emphasizes the contrasting heat transfer trends observed by the few independent studies available. As a matter of fact, the experimental analysis and development of accurate predictive 
methods for heat transfer and pressure drop in micro-pin fin geometries are limited by the complex fluid mechanics involved, which is tigthly correlated to the heat removal rate. More work is needed to create a larger experimental database of local flow boiling heat transfer coefficients rather than mean data, necessary for modeling purposes. In the majority of the cited studies, the wall temperature was evaluated by means of a 1D heat conduction model starting from a point value of the temperature measured by a thermocouple or a thermistor. Such 1D models do not account for lateral heat spreading, which was observed to significantly influence the widthwise temperature distribution at the channel wall in multi-microchannel evaporators [23]. The saturation temperature was nearly always considered to vary linearly between the inlet and the outlet measured values, without taking into account the actual non-linear two-phase pressure drop profile. A data reduction procedure better accounting for local temperature and pressure values, which merges together both temperature measurement and flow visualization, should potentially reduce the discrepancy among data from independent laboratories, and such tests are proposed here.

In this work, an infrared measurement technique is coupled with highspeed flow visualization to investigate the fluid dynamics and heat transfer associated with flow boiling in two micro-pin fins evaporators, one with inlet restrictions and one without. The infrared measurement technique provides a 2D thermal map of the micro-evaporator base, while the high-speed flow visualization yields a precious insight on the local two-phase flow patterns and the liquid-vapor interface time-dependent dynamics. This allows more 
information on the mutual dependency between flow configuration and heat transfer characteristics.

The micro-evaporator tested has a heated area of $1 \mathrm{~cm}^{2}$. The test section contains 66 rows of cylindrical micro-pin fins with an in-line configuration with a diameter, height and pitch of respectively $50 \mu \mathrm{m}, 100 \mu \mathrm{m}$ and $91.7 \mu \mathrm{m}$. The fluid utilized is refrigerant R236fa, since it was desired to have a low pressure fluid tested for future applications. Channel entrances with and without inlet restrictions are tested in order to evaluate their effect on the stability of the flow. The data reduction is based on a 3D heat conduction model utilized to extract the micro-pin fin footprint temperature, while the local fluid temperature along the test section is reconstructed based on a selected pressure drop model. Operational regimes, pressure drop and heat transfer performance of the two micro-evaporators (one with and one without inlet restrictions) are investigated for working conditions for mass fluxes varying from $500 \mathrm{~kg} \mathrm{~m}^{-2} \mathrm{~s}^{-1}$ to $2500 \mathrm{~kg} \mathrm{~m}^{-2} \mathrm{~s}^{-1}$ and heat fluxes ranging from $20 \mathrm{~W} \mathrm{~cm}^{-2}$ to $48 \mathrm{~W} \mathrm{~cm}^{-2}$. The exit saturation temperature is maintained at a fixed value of $30.5 \pm 0.5 \mathrm{~K}$ during these tests.

This paper is organized as follows: in Section 2 the experimental set-up and the test sections are described; in Section 3 the experimental procedure and the data reduction process are explained, together with single phase validation tests and results; in Section 4 the two-phase results are presented and discussed, while in the final Section 5 the main conclusions are drawn. 


\section{Experimental set-up}

In this section the experimental test facility and the micro-pin fins evaporator are described.

\subsection{Flow boiling test facility}

The experimental test facility consists of a closed loop of refrigerant, presented in Fig. 1. The test section is housed in a copper manifold installed along the circuit. In the loop, an oil-free micro-pump is utilized to drive the fluid, while a frequency controller and a Coriolis mass flow meter are adopted to set the refrigerant flow rate and to measure it with an accuracy of $0.35 \%$. The refrigerant is contained in a reservoir which is used to control the saturation pressure in the circuit, by changing its temperature with a RK 20 KP LAUDA compact low-temperature thermostat. Before the micro-pump, a $15 \mu \mathrm{m}$ filter is installed to prevent any contaminants from entering the test section. In order to set and modify the inlet flow temperature, a sub-cooler and an electrical pre-heater are installed upstream to the test section. Direct DC current is applied to heat up the electrical pre-heater and the test section by means of two Aluminium film heaters, as it will be explained later. The voltage drop across them and the current are measured via the National Instrument data acquisition system (NI DAQ) with a sampling rate of $1 \mathrm{kHz}$ over $1 \mathrm{~min}$ and then averaged. The refrigerant flows through the test section via the inlet and outlet manifold plenums, and it is afterwards condensed by a tube-in-tube heat exchanger. Thermocoax $0.25 \mathrm{~mm}$ K-Type thermocou-

ples are installed along the flow loop to evaluate the fluid temperature and keep the pre-heater wall temperature controlled, with an accuracy of $0.1^{\circ} \mathrm{C}$. 
There are two thermocouples in the manifold inlet and two in the outlet and their values are averaged to get inlet and outlet fluid temperature values. Absolute pressure measurements are performed by 10 bar absolute pressure transducers with a full-scale accuracy of $0.1 \%$, while a differential pressure transducer with a $0.023 \%$ full-scale accuracy is used to evaluate the total pressure drop between the inlet and the outlet manifold's plenums. Experimental uncertainties are listed in Table 1 . The test section, which will be described in detail in the following section, is placed in a copper manifold, used to provide and remove the refrigerant via the inlet and outlet manifold plenums. Two $10.5 \times 0.5 \mathrm{~mm}$ EPDM O-rings are positioned around the manifold plenums, and an EPDM gasket of $1 \mathrm{~mm}$ thickness is placed between the test section and the manifold cover to prevent leakage and reduce the mechanical stress on the test section. There are two openings in the copper manifold in order to allow optical access to both the bottom and the top side of the micro-evaporator. A Photron Fastcam-Ultima APX high-speed camera with a spatial resolution of $1024 \times 1024$ pixels and an acquisition frequency that can vary from $50 \mathrm{fps}$ to $2000 \mathrm{fps}$ is fixed above the test section to allow flow visualization. This is coupled with an AF Micro-Nikkor $105 \mathrm{~mm} 1: 2.8 \mathrm{D}$ lens and an additional ring. Below the test section, a ThermaCAM SC3000 high-speed IR camera, having a maximum frame rate of 900 fps, is installed in order to have a fully $2 D$ temperature map of the microevaporator bottom surface. The IR camera has a close up lens LW 34/80 to improve the accuracy of the measurement and to decrease the errors due to the surrounding temperature. For the present tests, a thermal pixel field of 110 by 110 pixels is obtained at a frequency of $60 \mathrm{~Hz}$. Each acquisition lasts 


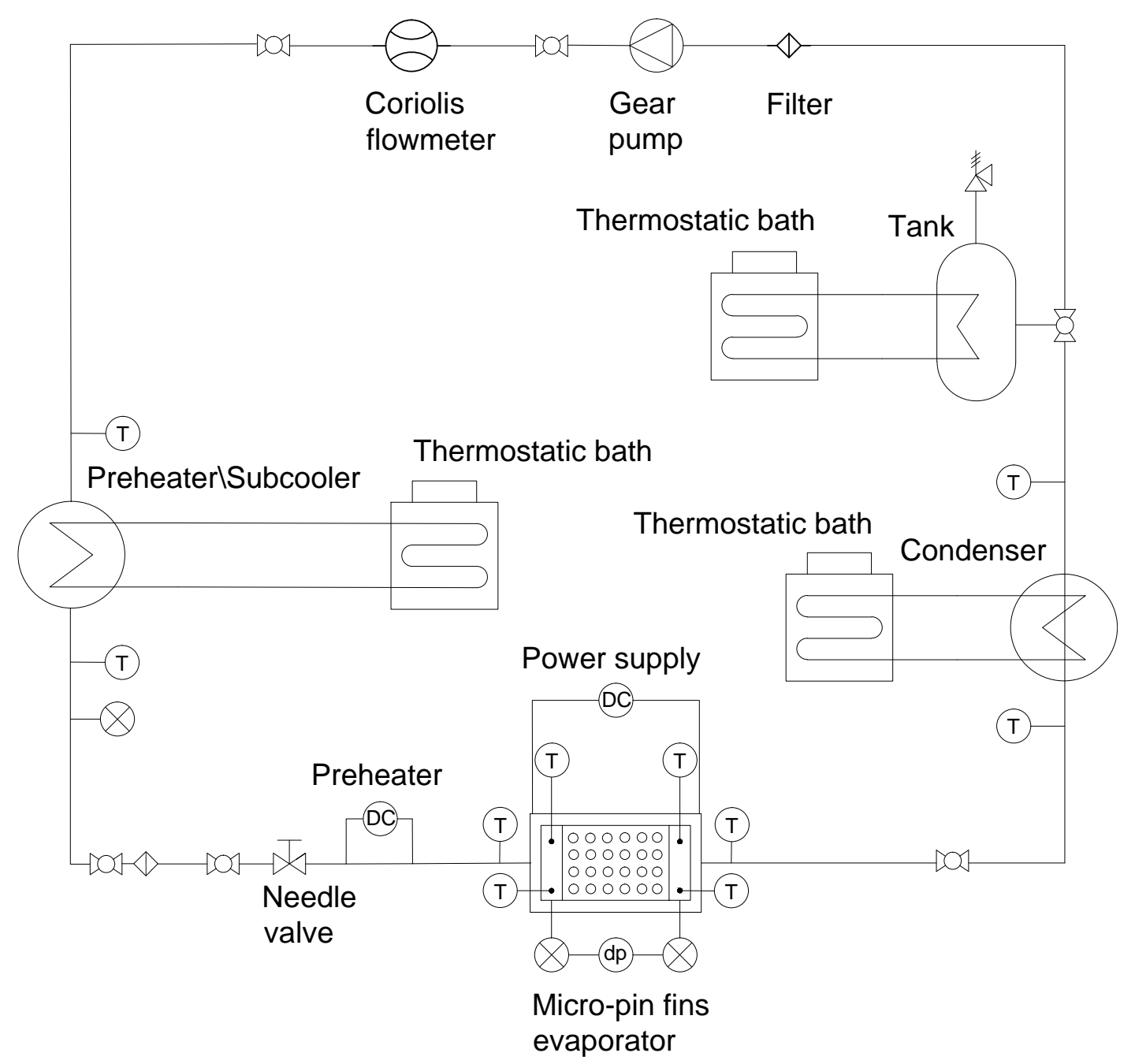

Figure 1: Schematic of the experimental flow loop.

for 30 seconds and the resulting 1800 frames are then averaged in time to obtain one temperature map. The infrared camera has been calibrated with 


\begin{tabular}{|c|c|}
\hline Parameter & Uncertainty \\
\hline$L, B, H[\mu \mathrm{m}]$ & \pm 5 \\
$W_{\text {ch }}, D_{\text {fin }}, H_{\text {fin }}[\mu \mathrm{m}]$ & \pm 5 \\
$W_{\text {restr }}[\mu \mathrm{m}]$ & \pm 5 \\
$G\left[\mathrm{~kg} / \mathrm{m}^{2} \mathrm{~s}\right]$ & $\pm 7 \%$ \\
$I[A]$ & $\pm 0.61 \%$ \\
$V[V]$ & $\pm 0.53 \%$ \\
$T_{\text {base }}\left[{ }^{\circ} \mathrm{C}\right]$ & \pm 0.2 \\
$p_{\text {in }}, p_{\text {out }}[\mathrm{kPa}]$ & $\pm 0.1 F S \%$ \\
$\Delta p_{\text {tot }}[\mathrm{kPa}]$ & $\pm 0.023 F S \%$ \\
$\Delta p_{\text {fin }}[\mathrm{kPa}]$ & $\pm 5.9 \%$ \\
$q_{\text {base }}\left[\mathrm{W} / \mathrm{cm}{ }^{2}\right]$ & $\pm 1.3 \%$ \\
$\operatorname{Re}[-]$ & $\pm 7 \%$ \\
$\operatorname{Re} \mathrm{tep}_{\mathrm{tp}}[-]$ & $\pm 9 \%$ \\
$f[-]$ & $\pm 15 \%$ \\
$\mathrm{Nu}[-]$ & $\pm 13.9 \%$ \\
$x[-]$ & $\pm 9.2 \%$ \\
$h_{w}[-]$ & $\pm 12 \%$ \\
\hline
\end{tabular}

Table 1: Experimental uncertainties. FS stands for full-scale.

a pixel by pixel calibration, in which all the pixels are calibrated individually performing adiabatic single phase tests at the maximum value of mass flow rate. More details on the IR camera calibration process can be found in [24]. The bottom surface of the test section was painted with a mat black spray 
in order to have a surface emissivity as close as possible to 1, thus improving the accuracy of the IR temperature measurements and reducing errors from the surrounding ambient.

\subsection{Micro-pin fins evaporator}

The test section is a silicon micro-evaporator with the dimensions of $25.4 \times$ $28 \mathrm{~mm}^{2}$, covered by a transparent Pyrex layer bonded on it. The flow region is

(a)

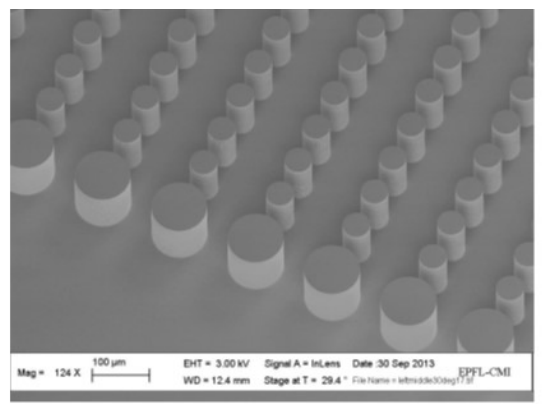

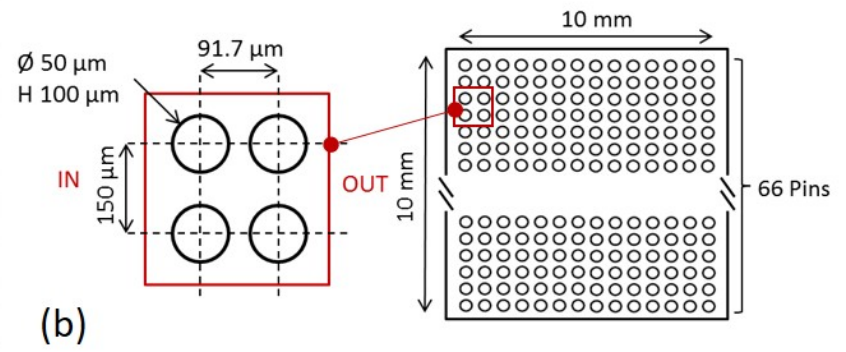

Figure 2: (a) Photograph from the microscope of micro-pin fins with the extra row of inlet restrictions (b) schematic of the pin-fin geometry with a zoom showing the configuration of the cylindrical pin fin.

traversed by in-line rows of circular micro-pin fins of diameter $D_{\text {fin }}=50 \mu \mathrm{m}$ and $H_{\text {fin }}=100 \mu \mathrm{m}$ height, covering a total heated surface of $L \times B=$ $1 \times 1 \mathrm{~cm}^{2}$, see Fig. 2. The pitch in the streamwise direction is equal to $91.7 \mu \mathrm{m}$ and in the widthwise direction is equal to $150 \mu \mathrm{m}$, thus having 67 channels of $W_{c h}=100 \mu \mathrm{m}$ width separated by 66 rows of in-line micro-pin fins. The microfabrication process was based on photolithography and a Deep Reactive Ion Etching (DRIE) process to etch the micro-pin fins in a $380 \mu \mathrm{m}$ thick double-side polished silicon wafer. The test sections were characterized by optical microscopy and Scanning Electron Microscopy (SEM). Finally, the 
silicon die was anodically bonded to a $525 \mu \mathrm{m}$ thick transparent Pyrex cover plate closing the channels from the top, see Fig. 3(a). The average surface roughness is about $40 \mathrm{~nm}$, which was measured with an optical profiler Veeco Wyko NT1100 and a mechanical profiler Bruker Dektak XT. The average electrical resistance of the microfabricated heaters, measured by an open probe station, is about $15 \Omega$. Two versions of the test section described above were fabricated and tested, one with and one without inlet restrictions. Inlet restrictions consist of an extra row of pin fins with a diameter of $100 \mu \mathrm{m}$ placed before the heated area, at the inlet of the test section, see Fig 2(a). The restrictions are characterized by their expansion ratio, which is defined as the ratio between the channels width $W_{c h}$ and the restrictions width $W_{\text {restr }}$, as follows:

$$
e_{\text {restr }}=\frac{W_{c h}}{W_{\text {restr }}}=2
$$

Previous studies of flow boiling within microchannels demonstrated that inlet restrictions suppress flow instabilities such as vapor back flow, which can block the flow passage and cause local dry-out [9]. Vapor back flow leads to high-amplitude and high-frequency temperature and pressure oscillations [25], which can damage or even break the micro-evaporator. Another advantage of inlet restrictions is that they promote vapor flashing. As explained by Park and Thome [26], when flashing is present the boiling starts at a lower heat flux, thus increasing the uniformity of the surface temperature.

On the bottom side of the test section there are two Aluminum film heaters of $1.5 \mu \mathrm{m}$ thickness, see Fig. 3(b), which are connected to the electrical power supply via an edge spring connector installed on a Printed Circuit Board (PCB) card. Each heater covers half of the heated area, and they can 


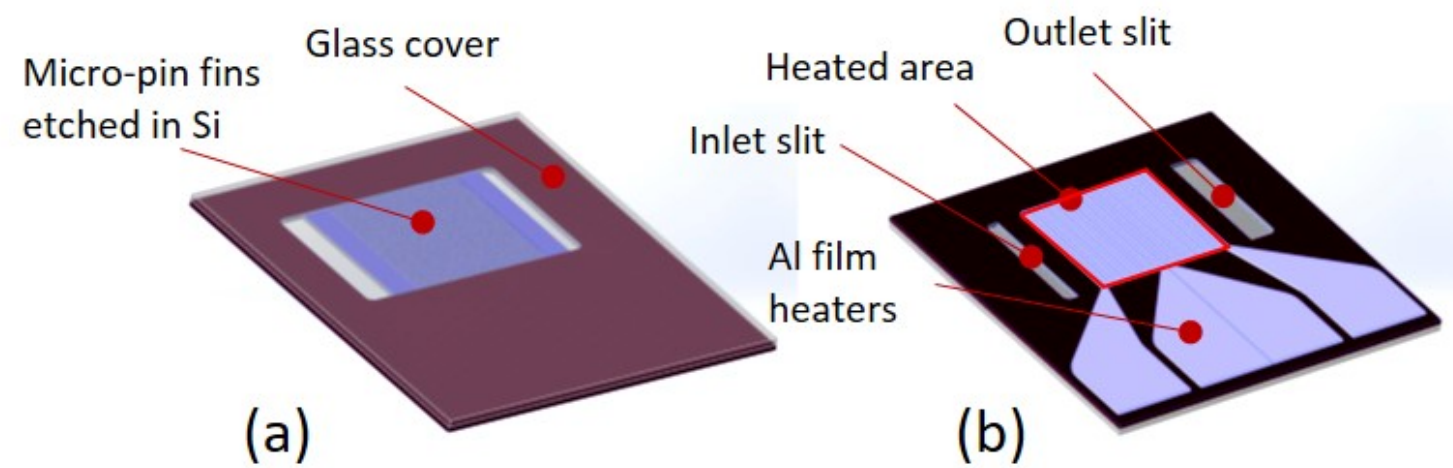

Figure 3: (a) Illustration of the top of the test section with the array of micro-pin fins etched in Silicon and then the glass cover bonded on it, (b) illustration of the bottom of the test section with the Aluminium (Al) film heaters.

be switched on together or separately in order to generate a non-uniform heat flux. The heat flux that can be applied to the $1 \mathrm{~cm}^{2}$ area of interest may vary between $0 \mathrm{~W} \mathrm{~cm}^{-2}$ and $100 \mathrm{~W} \mathrm{~cm}^{-2}$. The available power source associated with the micro-heater on the facility is a SORENSEN DLM32-95E: 0-32V, 0-95A.

\section{Experimental procedures and data reduction}

The properties of R236fa were taken from the REFPROP 8.0 software. R236fa is a low pressure refrigerant and its saturation pressure remained under 4 bar for all the performed tests. The heat flux ranged from $20 \mathrm{~W} \mathrm{~cm}^{-2}$ to $48 \mathrm{~W} \mathrm{~cm}^{-2}$, while the mass flux varied from $500 \mathrm{~kg} \mathrm{~m}^{-2} \mathrm{~s}^{-1}$ up to $2500 \mathrm{~kg} \mathrm{~m}^{-2} \mathrm{~s}^{-1}$, which corresponds to a range of the Reynolds number, calculated based on the equivalent channel diameter, between 171 and 1035. For all the experimental studies the outlet saturation temperature was equal to $30.5 \pm 0.5^{\circ} \mathrm{C}$ 
and the inlet liquid subcooling was set to $5.0 \pm 1.5 \mathrm{~K}$. The outlet saturation temperature was kept constant by adjusting the temperature of the RK 20 KP LAUDA compact low-temperature thermostat, while the inlet subcooling value was set by means of the pre-heater/subcooler.

The uncertainties of the measured values were obtained by means of the calibration procedures, while the uncertainties of the calculated parameters were estimated applying the method developed by Kline and McClintock [27]. All the uncertainties are listed in Table 1.

In this work, adiabatic and single phase tests were done as preliminary tests, not only to validate the reliability of the test facility, but also to evaluate the single phase friction factor and to characterize the heat losses, which will be both used in the successive two-phase data reduction. Below, single and two-phase data reduction procedures are presented in two separate subsections following the experimental procedure, which began with adiabatic and single phase tests.

\subsection{Single phase data reduction and validation}

First, adiabatic and diabatic single phase tests were performed for subcooled flow of R236fa within the two test sections. The first parameter to calculate is the adiabatic pressure drop along the pin fin array, $\Delta p_{\text {fin }}$, since it is used to extract the adiabatic single phase friction factor. The pressure drop along the pin fin array is evaluated from the total pressure drop, $\Delta p_{t o t}$, which is measured between the inlet and the outlet manifold's plenums with a differential pressure transducer, and then reduced with the inlet and outlet 
pressure drops, $\Delta p_{\text {in }}$ and $\Delta p_{\text {out }}$ :

$$
\begin{gathered}
\Delta p_{\text {fin }}=\Delta p_{\text {tot }}-\Delta p_{\text {in }}-\Delta p_{\text {out }} \\
\Delta p_{\text {in }}=\Delta p_{\text {cont } 1}+\Delta p_{\text {cont } 2}+\Delta p_{\text {cont } 3}+\Delta p_{\text {exp } 1} \\
\Delta p_{\text {out }}=\Delta p_{\text {exp } 2}+\Delta p_{\text {exp } 3}+\Delta p_{\text {exp } 4}
\end{gathered}
$$

The contributions to the inlet pressure drop are the pressure drop in the flow contractions between the inlet manifold's plenum and inlet slit $\Delta p_{\text {cont } 1}$, that between the inlet slit and the test section's plenum $\Delta p_{\text {cont } 2}$ and, when present, the pressure drop across the inlet restrictions $\Delta p_{\text {cont3 }}$. The inlet restrictions also add a pressure recovery due to the expansion into the channels, identified as $\Delta p_{\text {exp } 1}$. The outlet pressure drop consists of 3 recoveries due to the expansions between the channels and the outlet test section plenum $\Delta p_{\exp 2}$, between the test section plenum and the outlet slit, $\Delta p_{\exp 3}$, and between the outlet slit and the outlet manifold plenum $\Delta p_{\exp 4}$. All the contraction and the expansion pressure drops are computed according to the method of Lee and Garimella [28]:

$$
\begin{gathered}
\Delta p_{\text {cont }}=\left[1-\left(\frac{A_{2}}{A_{1}}\right)^{2}+K\right] \frac{G^{2}}{2 \rho_{l}} \\
\Delta p_{\text {exp }}=-2 \cdot 1.33+\left(\frac{A_{1}}{A_{2}}\right)\left[1-\left(\frac{A_{1}}{A_{2}}\right)\right] \frac{G^{2}}{2 \rho_{l}} \\
K=0.0088 \cdot a_{r}^{2}-0.1785 \cdot a_{r}+1.6027
\end{gathered}
$$

where $A_{1}$ and $A_{2}$ are the two cross-sectional areas, and $a_{r}$ denotes the channel aspect ratio (height to width) after the restriction in the contraction term. In the single phase test, the $\Delta p_{\text {fin }}$ was $75 \%$ of the total measured pressure drop, while the inlet pressure drop represented about the $28 \%$, and the outlet 
pressure recovery was about $3 \%$ of the total measured pressure drop.

The mass flux $G$ is evaluated from the mass flow rate $\dot{m}$ measured by the Coriolis mass flow meter, the total number of channels between the pin fin lines $N_{c h}\left(N_{c h}=67\right)$, their height $H_{\text {fin }}$ and width $W_{c h}$, as showed in the equation below:

$$
G=\frac{\dot{m}}{N_{c h} H_{f i n} W_{c h}}
$$

The single phase friction factor is evaluated from the calculated pressure drop along the pin fin array, as follows:

$$
f=\frac{\Delta p_{f i n} \rho_{l} D_{h}}{2 L G^{2}}, \quad D_{h}=\frac{4 A_{c h}}{P}
$$

where $L$ is the lenght of the heated area, $D_{h}$ is the hydraulic diameter of the channels, $P=2\left(H_{f i n}+W_{c h}\right)$ is the perimeter of the channel cross-section, and $A_{c h}=H_{\text {fin }} \cdot W_{c h}$ is its area.

Figure 4 plots the single phase friction factor for both micro-evaporators as a function of the Re number, which is defined as:

$$
\operatorname{Re}=\frac{G D_{h}}{\mu_{l}}
$$

For $\operatorname{Re}<300$, the friction factor decreases with increasing the Reynolds number following a $\mathrm{Re}^{-1}$ law, in agreement with the laminar flow theory. For larger Reynolds numbers, it stabilizes around a constant value of about 0.05. There is no appreciable difference between the case with inlet restrictions and the one without. Figure 5 displays the micro-pin fins pressure drop versus the mass flux, and the same transition is identified at a mass flux value of about $G=1000 \mathrm{~kg} \mathrm{~m}^{-2} \mathrm{~s}^{-1}$, which corresponds to $\mathrm{Re}=300$. The increase of the pressure drop with mass flux is more pronounced above this threshold 
value.

A transition in the friction factor trend at much lower Reynolds number values than those predicted by the laminar flow theory was already observed by Prasher et al. [29] for a staggered pin fin configuration with water flow, thus emphasizing that the pin fin are playing an important role on the friction factor. A similar change in the pressure drop profile was also reported by

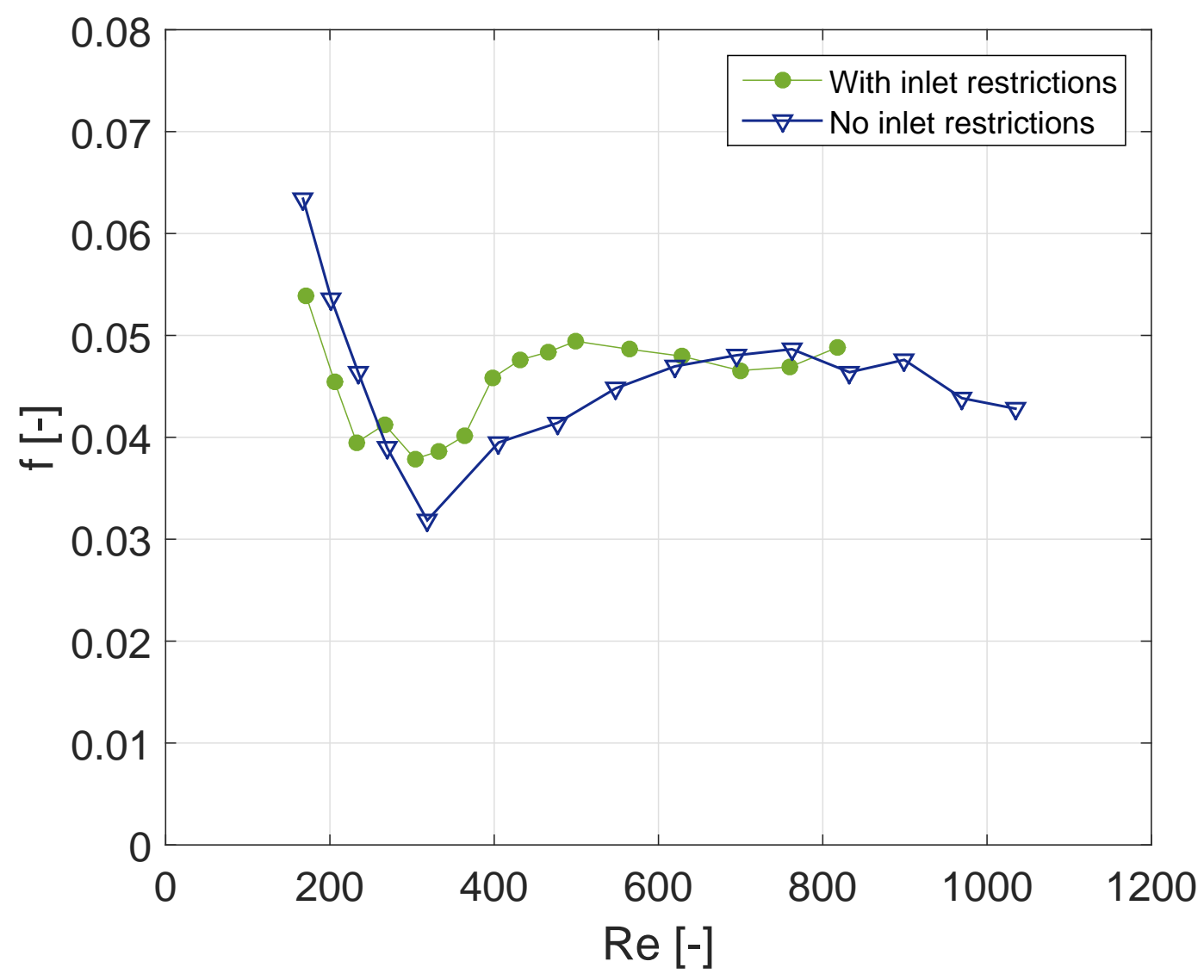

Figure 4: Single phase friction factor as a function of the Reynolds number for the test sections with and without inlet restrictions. 
Renfer et al. [30] for $\mathrm{Re}=350$ and a staggered pin fin configuration. They motivated this trend with the onset of vortex shedding behind the pin fin. In particular, they noticed that at low Reynolds numbers the fluid between

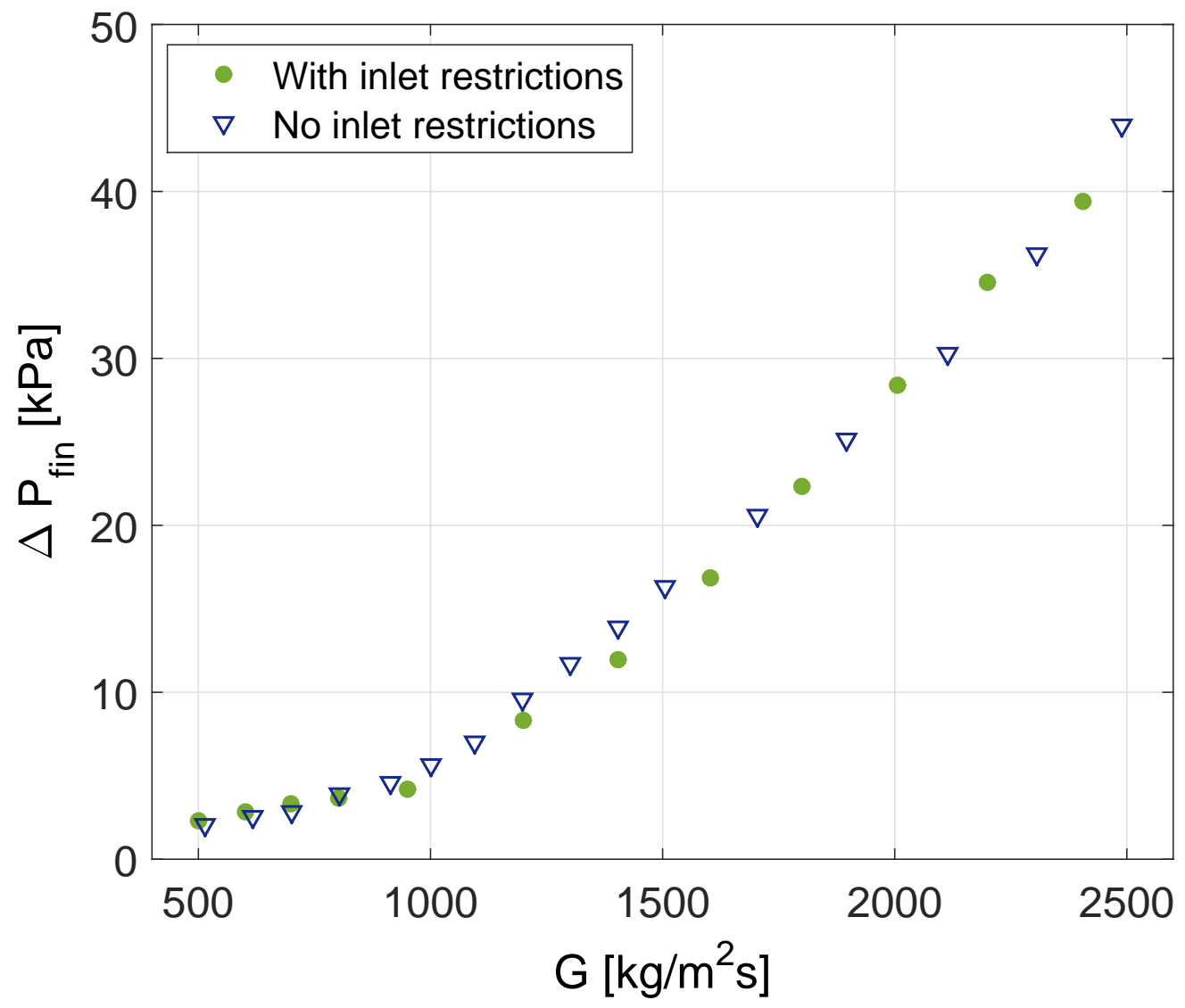

Figure 5: Pressure drop along the micro-pin fins array as function of the mass flux for test sections with and without inlet restrictions.

the obstacles recirculated without mixing with the channel-like flow, while at higher Reynolds numbers time-dependent patterns triggered mixing between the recirculating wake and the channel-like flow, thus yielding a rise of the 
pressure drop. The theory of flow past a cylinder indicates a transition to vortex shedding in the wake behind the obstacle at a value of Re number, defined with the cylinder diameter, of 250. This value is on the same order as the threshold value seen in the present experiments $(\mathrm{Re}=150$ when calculated using the pin fin diameter as the reference length), thus further confirming that vortex shedding may be the actual reason of the transition evident in Figs. 4 and 5. Actually, the transition occurs at lower Re values than those reported for flow past a cylinder, which is consistent with the more disturbed flow configuration, characterized by low aspect ratio obstacle arrays (as opposed to a single, infinitely extended cylinder) which interact with each other.

In order to validate the single phase heat transfer performance versus the available correlations, diabatic tests were performed. As the heat transfer performance indicator, an average Nusselt number is calculated here:

$$
\overline{\mathrm{Nu}}=\frac{\overline{h_{w}} D_{h}}{k}
$$

where $k$ is the fluid thermal conductivity and $\overline{h_{w}}$ is the average wall heat transfer coefficient, which is calculated by solving an inverse 3D heat conduction problem, as explained below.

Starting from the 2D temperature map given by the IR camera for the bottom surface of the micro-evaporator $T_{\text {base }}$, an inverse heat conduction problem through the heat sink volume is formulated and solved to derive the footprint temperature $T_{f t p}$, and heat flux $q_{f t p}$. The numerical solution is based on a self-implemented finite-volume method to solve the steady-state 3D heat conduction problem coupled with an optimization algorithm based on the Newton-Raphson method. The 3D heat conduction equation is solved with 
the following boundary conditions:

- Micro-evaporator base: base heat flux $q_{b a s e}$ calculated via the electrically applied total power $Q_{e l}$ reduced by the heat losses $Q_{\text {losses }}$, $q_{\text {base }}=\left(Q_{e l}-Q_{\text {losses }}\right) / A_{\text {base }}$, where $A_{\text {base }}=L B$ is the heated area; the value of $T_{\text {base }}$ is not used at this stage but it will be used in the optimization procedure.

- Micro-evaporator lateral sides: imposed heat flux evaluated based on the Fourier law where the temperature gradient orthogonal to the micro-evaporator sides is estimated based on the 2D base temperature map; heat fluxes vary along the perimeter of the micro-evaporator base according to the IR reading, but are considered constant along the height of the micro-evaporator.

- Micro-evaporator footprint: constant temperature boundary condition is imposed, where the temperature values are optimized according to the Newton-Raphson method.

At the first iteration, the 3D heat conduction problem is solved with a footprint temperature condition derived from the IR camera reading $T_{f t p}^{0}=$ $T_{\text {base }}-q_{\text {base }} H / k_{\text {sil }}$, where $q_{\text {base }} H / k_{\text {sil }}$ is an estimation of the temperature drop along the micro-evaporator height based on 1D heat conduction. The thermal conductivity of silicon $k_{\text {sil }}$ is evaluated as a parabolic function of temperature [31].

For the successive iterations, the footprint temperature is updated according 
to the optimization algorithm, with the objective of decreasing the maximum deviation between the base temperature read by the IR camera and that obtained by the finite-volume method $T_{\text {base }, F V}$ :

$$
\operatorname{dev}=\max \left|T_{\text {base }}-T_{\text {base }, F V}\right|
$$

below a threshold value of $0.05^{\circ} \mathrm{C}$. The local footprint heat flux and temperature fields obtained as the solution of the inverse heat transfer problem are then used to estimate the local footprint heat transfer coefficient $h_{f t p}$ :

$$
h_{f t p}(y, z)=\frac{q_{f t p}(y, z)}{T_{f t p}(y, z)-T_{f l}(y, z)}
$$

Here, the local single phase fluid temperature $T_{f l}$ is evaluated by means of an energy balance applied between the inlet of the heated area and a generic $y, z$ location:

$$
T_{f l}(y, z)=T_{i n}+\frac{B}{\dot{m}} \int_{0}^{z} \frac{q_{f t p}(y, z)}{c_{p}(y, z)} d z
$$

where $T_{i n}$ is the temperature measured in the inlet manifold, and $B$ is the test section width. Finally, the local wall heat transfer coefficient necessary for the calculation of the Nusselt number in Eq. (11) is derived applying the fin efficiency according to the following equations:

$$
\begin{gathered}
h_{w}(y, z)=\frac{h_{f t p}}{A_{b}}\left(A_{b}-\frac{\pi D_{f i n}^{2}}{4} N_{f i n}+\eta_{f i n} \pi D_{f i n} H_{f i n} N_{f i n}\right) \\
\eta_{f i n}(y, z)=\frac{\tanh \left(m H_{f i n}\right)}{\left(m H_{f i n}\right)} \\
m(y, z)=2 \sqrt{\frac{h_{w}}{k_{\text {sil }} D_{f i n}}}
\end{gathered}
$$

where $N_{f i n}$ is the total number of micro-pin fins. The above Eqs. (15)-(17) are solved iteratively to yield the local wall heat transfer coefficients, giving 
a $2 \mathrm{D}$ map characterized by $110 \times 110$ values. This heat transfer coefficient field is then averaged along the widthwise and streamwise directions in order to extract average parameters, such as the Nusselt number in Eq. (11). Fig-

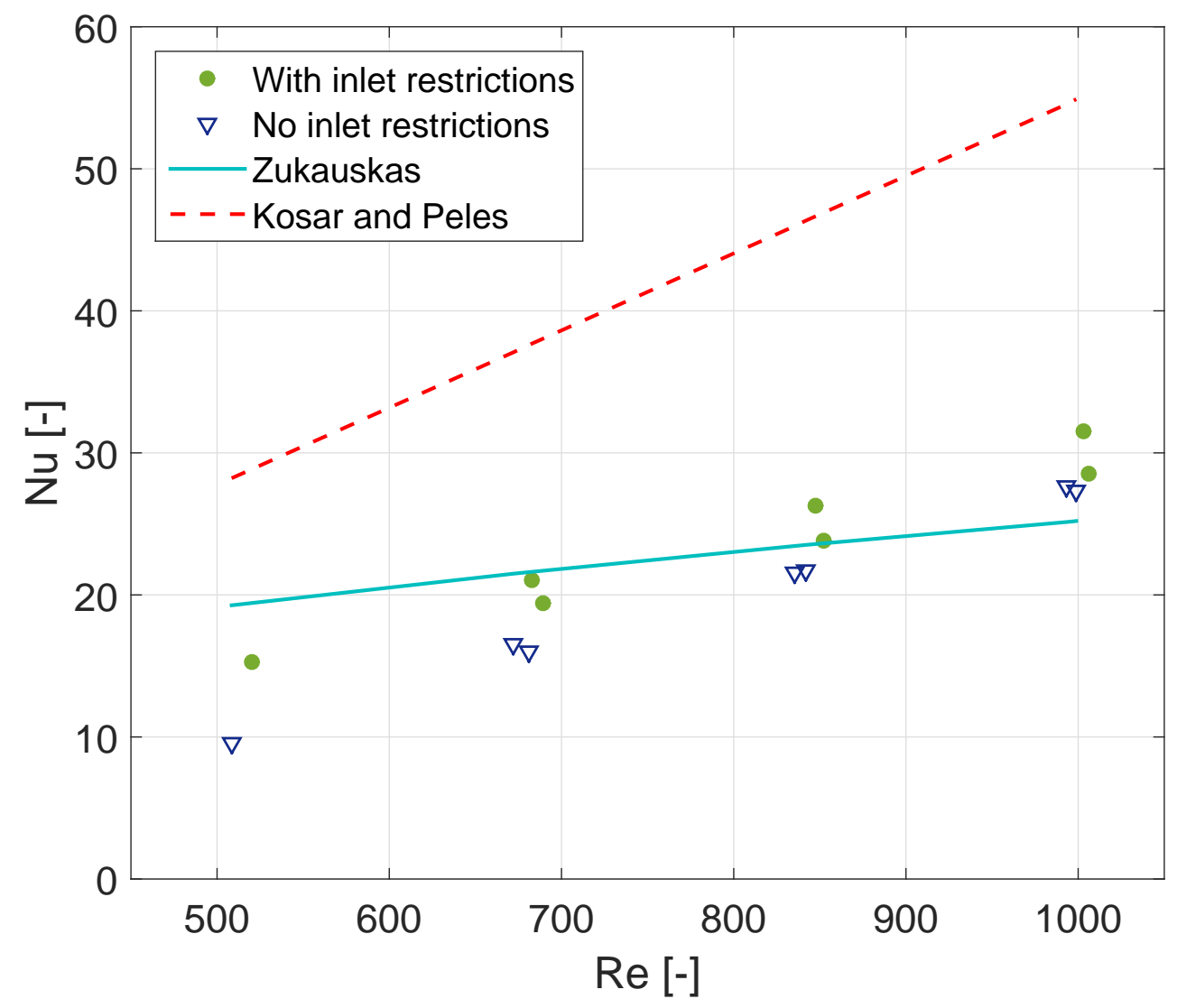

Figure 6: Average Nusselt number for both the geometries and comparison with Zukauskas correlation for tube bundles [32] and Kosar and Peles for micro-pin fins [17].

ure 6 reports the single phase average Nusselt number obtained by the data reduction explained above as a function of the Reynolds number. The heat transfer performance augments with the Reynolds number which is expected 
as a consequence of the enhanced fluid mixing promoted by the vortex shedding phenomenon. The data for the geometry with inlet restrictions agree very well with the Zukauskas correlation [32], which was developed for tube bundles $\left(H_{\text {fin }} / D_{\text {fin }}>8\right)$, while the Kosar and Peles correlation [17], obtained by modyfing the Zukauskas correlation to predict their experimental data at low Reynolds number, sistematically overestimates the present data.

The heat losses for the single phase tests are calculated based on the following energy balance:

$$
Q_{\text {losses }}=Q_{e l}-\dot{m} c_{p}\left(T_{\text {in }}-T_{\text {out }}\right)
$$

where $Q_{e l}$ is the total electrical power input measured from the voltage and current imposed in the aluminium film heaters, $Q_{e l}=V I$, while $T_{i n}$ and $T_{\text {out }}$ are the fluid temperatures measured at the inlet and outlet manifold, respectively. For the single phase tests the heat losses were estimated to be maximum the $18 \%$ of the total applied electrical power $Q_{e l}$. For the twophase flow experiments the energy balance is not applicable, and therefore a correlation to predict the heat losses as function of the temperature difference between the average base temperature and the ambient, and the applied electrical heat flux, is extracted from the single phase experiments. Using a nonlinear least-squares fit with a maximum error of $5 \%$, the equation adopted to estimate the two-phase heat losses is the following:

$$
Q_{\text {losses }}=0.0937\left(T_{\text {base }}-T_{\text {amb }}\right)+1.3952 \cdot 10^{-5} q-0.0918
$$

where $q=Q_{e l} / A_{\text {base }}$ is the nominal electrical heat flux and it will be used in the remainder of the paper to indicate the tested heat flux. The maximum 
heat loss under the present experimental conditions was $9 \%$ of the total applied elecrical power input. Note that the heat losses associated with twophase flow are lower than those measured for single phase at the same heat flux conditions because, due to the better heat removal capability of the two-phase flow, the evaporator base temperature used in Eq. (19) is lower.

\subsection{Two-phase data reduction}

The main goal of the current research is to evaluate the pressure drop and the heat transfer performance of a micro-pin fins evaporator under flow boiling conditions. The total pressure drop, which is a meaningful indicator of the required pumping power of the system, is readable from the differential pressure transducer. From the total pressure drop, the pressure drop along the pin fin array can be evaluated by subtracting the inlet and outlet pressure drops, as indicated in Eq. (2). Since the fluid at the inlet is still subcooled, Eq. (3) is adopted to calculate the inlet pressure drop. However, the fluid at the outlet section is in two-phase state, and hence Eq. (4) and the Garimella and Lee correlations [28] used for the expansion contributions in single phase cannot be utilized in the two-phase case. The procedure chosen to estimate the outlet pressure drop is based on a preliminary two-phase half-heating test, as already described by Costa-Patry et al. [33] and Szczukiewicz et al. [34]. This was performed by switching on only the first aluminium heater, thus forming an adiabatic two-phase flow toward the end of the chip. By assuming that the fluid at the end of the flow area is at saturation conditions and at the same temperature of the micro-evaporator bottom surface, the pressure at the end of the pin fin array was taken equal to the saturation pressure corresponding to the local reading of the IR camera, i.e. the local 
adiabatic saturation temperature. Therefore, the outlet pressure drop could be evaluated as the difference between this local value and the measured outlet pressure. In order to extend the half-heating results to the full heating case, the values of $\Delta p_{\text {out }}$ were correlated to the outlet vapor quality $x_{\text {out }}$ and the mass flux $G$ as follows:

$$
\Delta p_{\text {out }}=9.828\left(x_{\text {out }} \frac{G}{G_{\text {min }}}\right)^{0.2675}-10.9
$$

where $G_{\min }$ is the minimum value of the mass fluxes tested. The two-phase wall heat transfer coefficient $h_{w}$, is derived from the footprint value $h_{f t p}$ as reported in Eq. (15), while $h_{f t p}$ is calculated from the footprint heat flux and temperature, see Eq. (13), obtained from the 3D heat conduction procedure applied to the two-phase infrared temperature measurements. For evaluating the fluid temperature $T_{f l}$, the heated area is divided into single phase and two-phase zones. In the single phase zone the fluid is subcooled, and the local fluid temperature is estimated by applying the energy balance as indicated in Eq. (14). Simultaneously, the local fluid pressure $p_{l o c}$ is computed from the value at the inlet of the pin fin region $\left(p_{i n, f i n}=p_{i n}-\Delta p_{i n}\right.$, where $p_{\text {in }}$ is the pressure measured at the inlet manifold) reduced by the frictional single phase pressure drop:

$$
p_{l o c}(y, z)=p_{\text {in, fin }}-\int_{0}^{z} \frac{2 f G^{2}}{D_{h} \rho_{l}(y, z)} d z
$$

where $f$ in Eq. (21) is the single phase friction factor evaluated in the preliminary adiabatic single phase tests. The local fluid saturation temperature is computed from its local pressure, $T_{\text {sat }}(y, z)=T_{\text {sat }}\left[p_{l o c}(y, z)\right]$. In this initial subcooled region, the fluid temperature increases almost linearly with the streamwise location $z$, while the local saturation temperature decreases due 
to the pressure drop. Figure 7 depicts the reconstructed local fluid and saturation temperatures along the micro-evaporator for a selected case. When

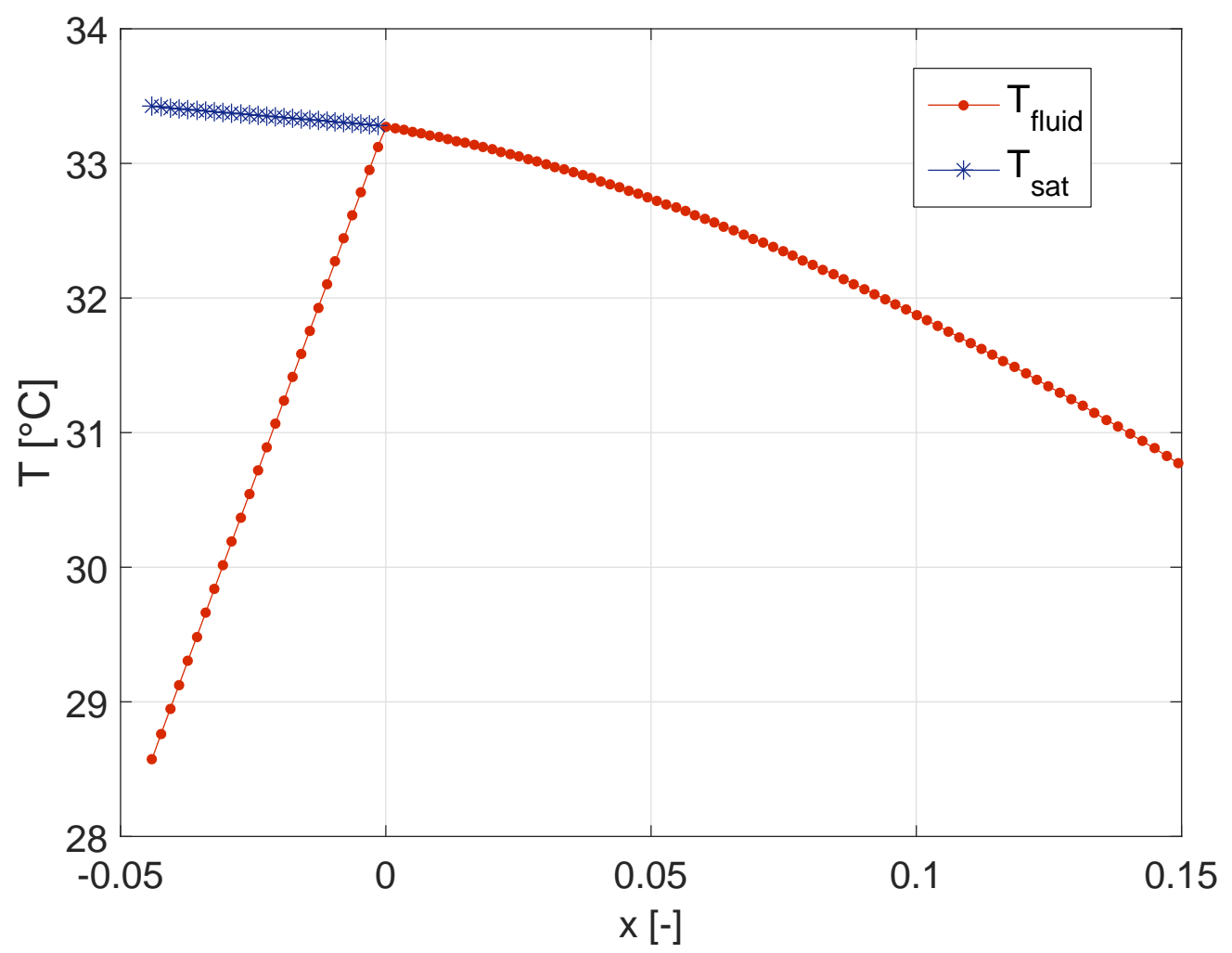

Figure 7: Local fluid temperature and saturation temperature as function of the vapor quality, at conditions of $q=36 \mathrm{~W} \mathrm{~cm}^{-2}$ and $G=1500 \mathrm{~kg} \mathrm{~m}^{-2} \mathrm{~s}^{-1}$. In the single phase zone the fluid temperature increases linearly following the energy balance, while in the two-phase flow zone it decreases following the pressure drop profile.

the fluid temperature in the single phase region reaches the saturation value, transition to two-phase flow is considered to occur. In the following two- 
phase region, the vapor quality locally varies with the specific enthalpy $i$ :

$$
x(y, z)=\frac{i(y, z)-i_{L}\left[p_{l o c}(y, z)\right]}{\left.i_{L V}\left[p_{l o c}(y, z)\right]\right)}
$$

where the local enthalpy is derived by means of an energy balance. In the two-phase region, the fluid temperature cannot be evaluated via the energy balance, but it is estimated as the saturation temperature corresponding to the local pressure $p_{l o c}$. Rather than considering a linear pressure profile in the two-phase region as done in most of the experimental studies conducted so far (which is appropriate only when the pressure drops are small), here the local pressure is reconstructed by using an empirical pressure drop model with a correction to match the experimental pressure measured at the outlet manifold [24]. Starting from the local pressure at the point where the twophase flow begins $z_{t p}$, the pressure profile is estimated by subtracting the accelerational and frictional pressure drops according to the homogeneous model:

$$
p_{l o c}(y, z)=p_{l o c}\left(y, z_{t p}\right)-\int_{z_{t p}}^{z} d p_{a, f i n}(y, z)-\int_{z_{t p}}^{z} d p_{f, f i n}(y, z)
$$

where:

$$
\begin{gathered}
d p_{a, f i n}(y, z)=G^{2}\left[\frac{1}{\rho_{v}(y, z)}-\frac{1}{\rho_{l}(y, z)}\right] d x \\
d p_{f, f i n}(y, z)=2 f_{t p}(y, z) G^{2}\left[\frac{x(y, z)}{\rho_{v}(y, z)}-\frac{1-x(y, z)}{\rho_{l}(y, z)}\right] \frac{d x}{D_{h}}
\end{gathered}
$$

where $d x$ is the variation in vapor quality in the infinitesimal lenght $d z$, and $f_{t p}$ denotes the two-phase friction factor evaluated as:

$$
f_{t p}(y, z)=\frac{16}{\operatorname{Re}_{\mathrm{tp}}(y, z)}, \quad \operatorname{Re}_{\mathrm{tp}}(y, z)=\frac{G D_{h}}{\mu_{t p}(y, z)}
$$


The two-phase viscosity is evaluated by the Cicchitti correlation [35]:

$$
\mu_{t p}(y, z)=\mu_{v}(y, z) x(y, z)+\mu_{l}(y, z)[1-x(y, z)]
$$

Once the pressure profile along the whole test section is reconstructed, the $\Delta p_{\text {fin }}$ calculated for the two-phase region is rescaled in order for the total $\Delta p_{\text {fin }}$ (summing the single phase and two-phase zones contributions) to match the value reduced from the experimental data. The pressure profile is finally recalculated according to this correction, and the fluid temperature in the two-phase region is taken as the saturation temperature corresponding to the corrected pressure profile. Since the pressure drops increase along the test section, the resulting local fluid temperature does not decrease linearly, as can be observed in Fig. 7 for a selected case.

\section{Two-phase results}

The two-phase flow boiling results are outlined and discussed in this section. In Section 4.1, the test section operational maps developed thanks to the coupling of high-speed flow visualization and IR temperature measurements are presented. The pressure drop and heat transfer performance of the micro-evaporators (with and without inlet restrictions) are shown in Sec-

tions 4.2 and 4.3, respectively, and a comparison to prior multi-microchannel evaporator results is proposed. All the uncertainties of the data presented are listed in Table 1.

\subsection{Operational maps}

In order to better understand the mutual effect of fluid dynamics and heat transfer in the micro-pin fins evaporator under flow boiling conditions, 
the videos obtained by the high-speed camera were analyzed in conjunction with the $2 \mathrm{D}$ thermal map given by the IR camera. The high-speed camera has a spatial resolution of $1024 \times 1024$ pixels at $2000 \mathrm{fps}$, while the IR camera of $320 \times 240$ pixels at $60 \mathrm{fps}$, out of which an array of $110 \times 110$ pixels covers the heated area. The flow videos and IR measurements are recorded for 30 s. The high-speed video and time-dependent local values of the temperature are then processed to identify the operational regime characterizing the flow conditions set, as it is explained below for a specific case.

Figure 8 shows an example of the simultaneous analysis of thermal field and

(a)
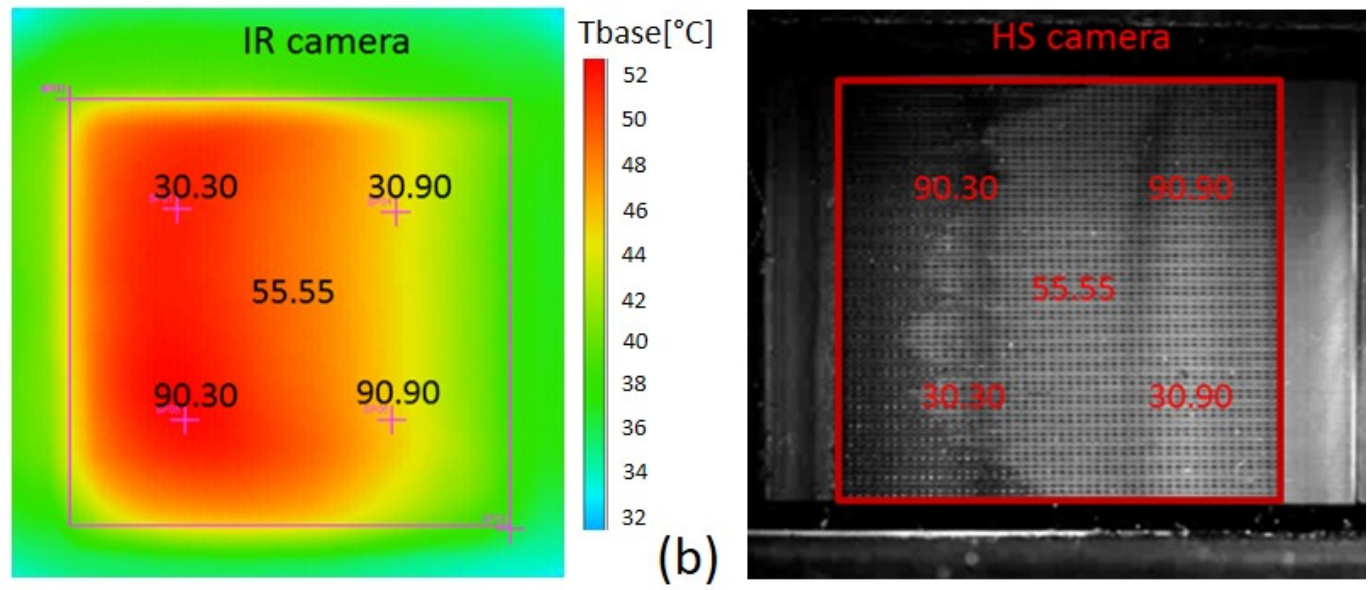

Figure 8: (a) Thermal map from the IR camera and (b) screenshot from the high-speed camera taken simultaneously for test conditions of $q=44 \mathrm{~W} \mathrm{~cm}-2$ and $G=2000 \mathrm{~kg} \mathrm{~m}^{-2} \mathrm{~s}^{-1}$, test section with inlet restrictions. The square drawn in the figures identifies the heated area. Flow is from left to right.

flow visualization for a selected set of operating conditions in the presence of inlet restrictions. In the figure, the heated section is highlighted by a square, 
and flow is from left to right. From the infrared temperature contours it can be seen that the evaporator temperature decreases as the end of the channel is approached. Analysis of the high-speed video reveals that flow is still single phase nearby the channel inlet (darker region in Fig. 8(b)) where the temperature is higher, while the development of the two-phase flow in the following zone (brighter region in Fig. 8(b)) yields a reduction of the microevaporator temperature. A more quantitative investigation is performed by tracking the temperature behaviour versus time extracted from the IR reading for five selected pixels distributed nearby the inlet, the center, and the outlet of the heated area (see pixels location in Fig. 8).

Figure 9(a) displays the time-temperature plot extracted from the IR camera reading during the $30 \mathrm{~s}$ aquisition period for the case reported in Fig. 8, while Fig. 9(b) shows the same plot for a case characterized by lower mass flux and heat flux. Figure 9(a) confirms that the lowest values of temperature are detected toward the end of the heated area, where the flow visualization image presented in Fig. 8(b) revealed that the two-phase flow is present, thus emphasizing the beneficial effect the two-phase flow in cooling down the micro-evaporator. Temperature oscillations in time are small; a statistical analysis was performed and it yielded a standard deviation varying from $0.039{ }^{\circ} \mathrm{C}$ to $0.051^{\circ} \mathrm{C}$ for the measurements taken at the five pixels. The high-speed video showed a temporally stable transition from single phase to two-phase flow, as such the operational regime corresponding to this set of operating conditions is marked as stable single phase flow followed by two-phase flow. Also in the case reported in Fig. 9(b) the lowest values 


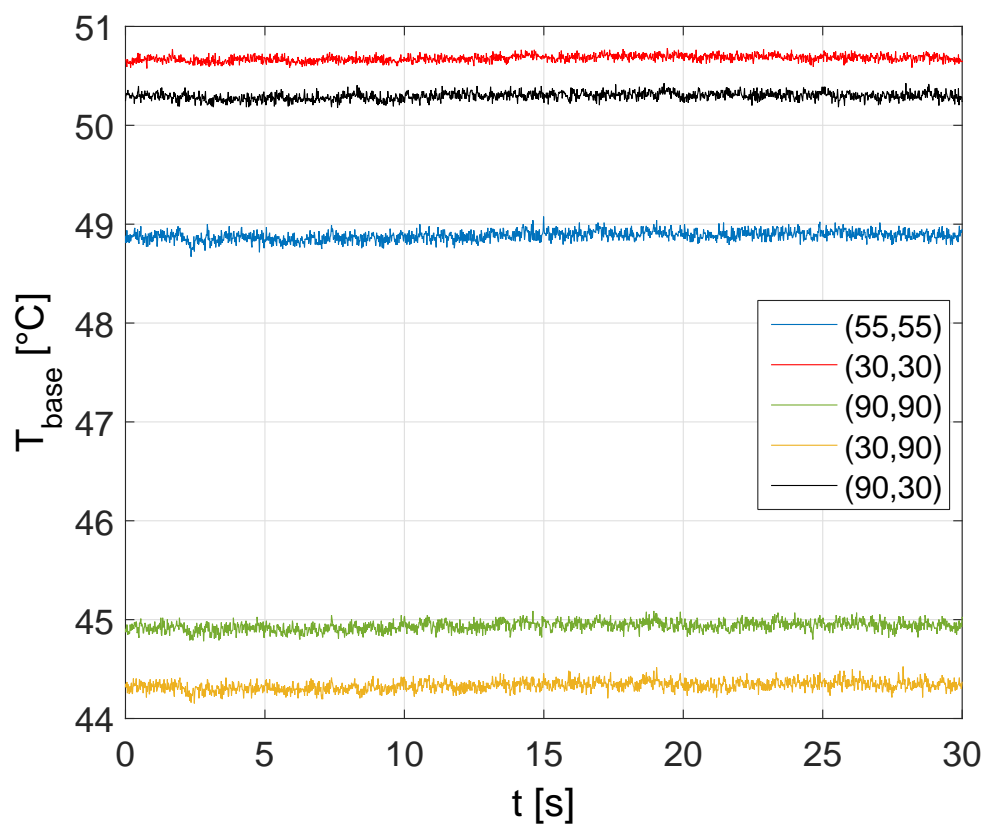

(a) $q=44 \mathrm{~W} \mathrm{~cm}^{-2}, G=2000 \mathrm{~kg} \mathrm{~m}^{-2} \mathrm{~s}^{-1}$

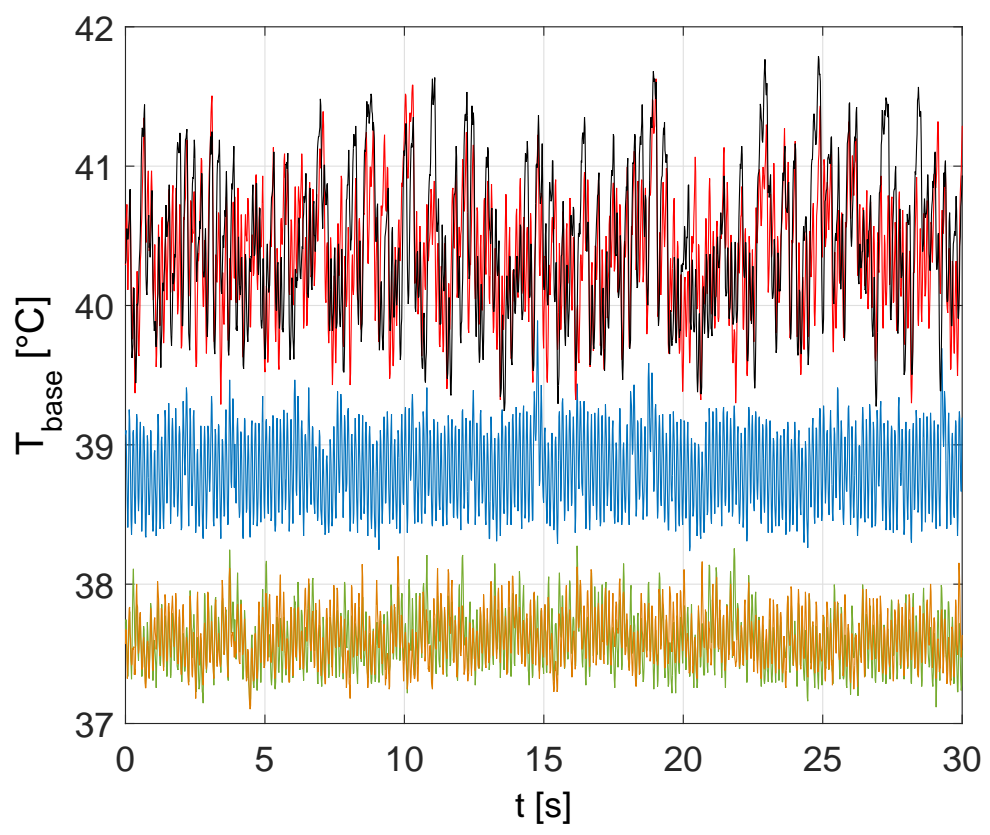

(b) $q=28 \mathrm{~W} \mathrm{~cm}^{-2}, G=750 \mathrm{~kg} \mathrm{~m}^{-2} \mathrm{~s}^{-1}$

Figure 9: Temperature versus time measured by the IR camera for 5 selected pixels (see Fig. 8(a)) within the heated area, for two different test conditions both characterized by the presence of inlet restrictions. 
of temperature are achieved toward the end of the heated area, although the temperature oscillations are visibly much larger, especially nearby the inlet. The high-speed video reveals strong unstable time-dependent patterns of the liquid-vapor interface in particular at the heated section inlet, thus motivating the plot in Fig. 9(b) where the average amplitude of the temperature oscillations is of $0.12{ }^{\circ} \mathrm{C}$ for the pixels located nearby the exit, but it rises up to $0.28^{\circ} \mathrm{C}$ nearby the entrance. These flow conditions are identified as unstable two-phase flow, although these temperature fluctuations are not that severe for cooling of electronics.

By adopting the same procedure explained above, the operational regimes for each of the experimental conditions tested were classified into different categories to generate the operational maps presented in Fig. 10. Every point in the operational map represents a test condition, identified by its mass flux $G$ and heat flux $q$. Five different operating flow types were distinguished:

1. Single phase flow $(\bigcirc)$;

2. Jet-flow $(\bigcirc)$;

3. Stable single phase flow followed by two-phase flow (O);

4. Unstable two-phase flow with back flow $(O)$;

5. Fully stable two-phase flow initiated from the beginning of the test section from flashed vapor bubbles $(\bigcirc)$;

In Fig. 11 snapshots of the high-speed videos related of each of the twophase flow operational regimes are illustrated in order to further clarify the dinstinction among the regimes identified. Full single phase flow regime is observed only for the micro-evaporator with inlet restrictions, at the highest 

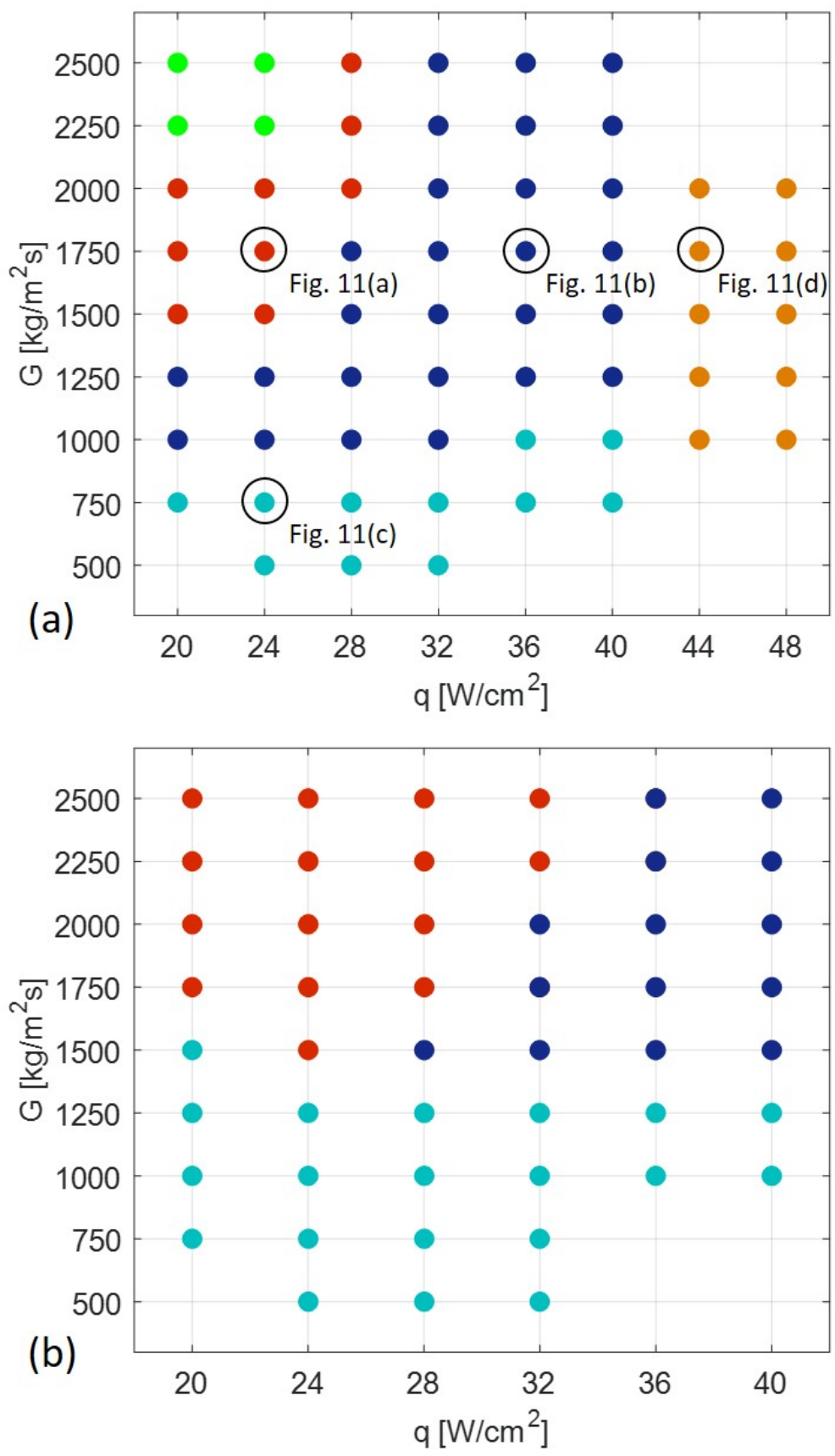

Figure 10: Two-phase flow operational maps for the test section (a) with inlet restrictions and (b) without inlet restrictions. Five flow regimes are identified: $\bigcirc$ single phase; jet-flow; stable single-phase flow followed by two-phase flow; $\bigcirc$ unstable two-phase flow with back flow; $\bigcirc$ fully stable two-phase flow.

values of mass flux and lowest values of heat flux tested (top-left region in plot in Fig. 10(a)), because the thermal energy provided is not sufficient to 

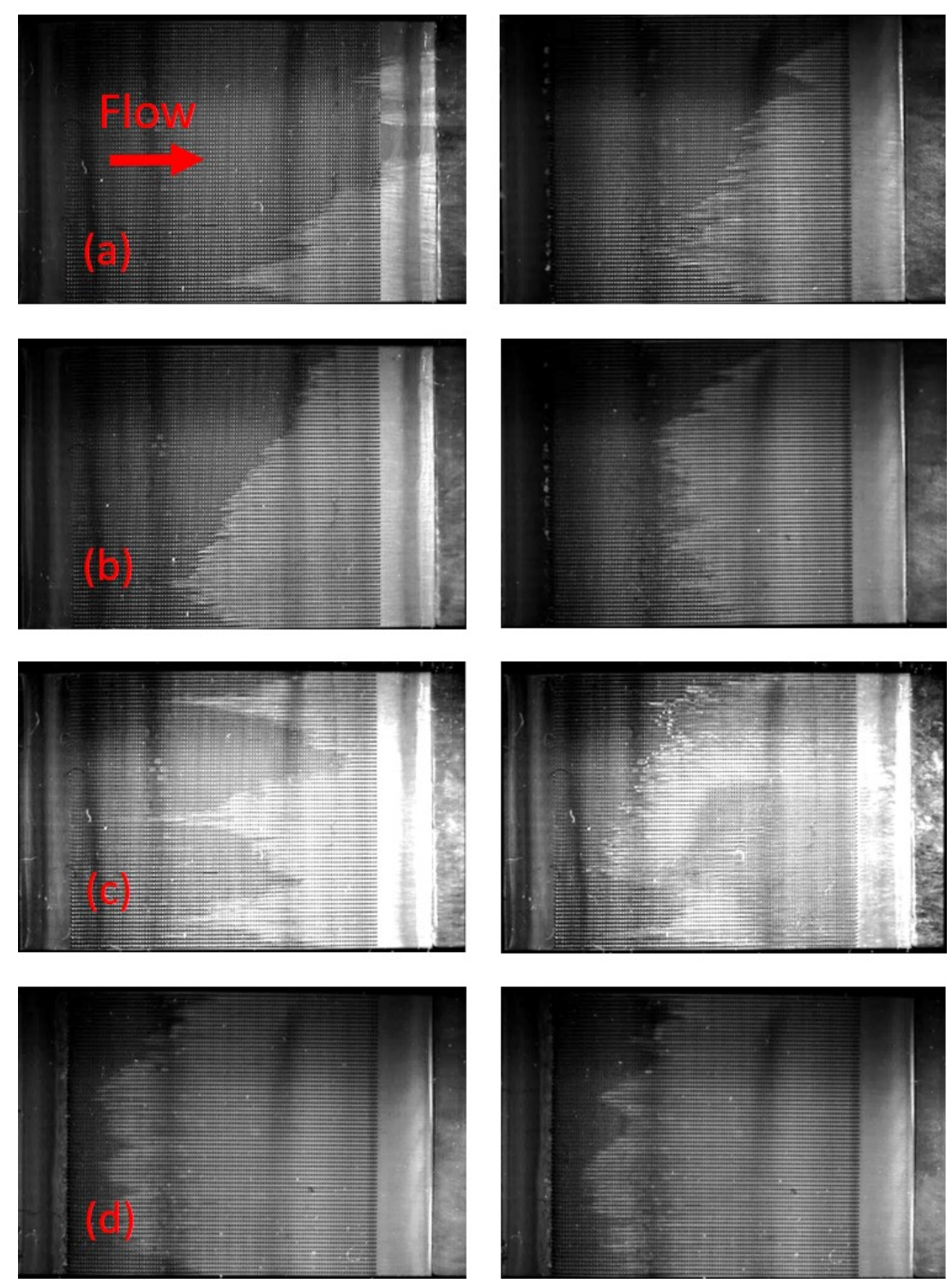

Figure 11: Screenshots from the high-speed camera of the four two-phase flow regimes showed in the operational maps for the case with inlet restrictions. For every flow regime 2 different time instants are showed in order to emphasize the time-dependent nature of the flow. (a) jet-flow $q=24 \mathrm{~W} \mathrm{~cm}^{-2}$ and $G=1750 \mathrm{~kg} \mathrm{~m}^{-2} \mathrm{~s}^{-1}$, (b) single phase followed by two-phase flow $q=36 \mathrm{~W} \mathrm{~cm}^{-2}$ and $G=1750 \mathrm{~kg} \mathrm{~m}^{-2} \mathrm{~s}^{-1}$, (c) unstable two-phase flow $q=24 \mathrm{~W} \mathrm{~cm}^{-2}$ and $G=750 \mathrm{~kg} \mathrm{~m}^{-2} \mathrm{~s}^{-1}$, and (d) fully stable two-phase flow $q=48 \mathrm{~W} \mathrm{~cm}^{-2}$ and $G=1750 \mathrm{~kg} \mathrm{~m}^{-2} \mathrm{~s}^{-1}$. Flow is from left to right.

initiate two-phase flow. For slightly larger $q$ and lower $G$, two-phase flow is initiated toward the end of the test section at fixed locations. From these stable nucleation points, two-phase flow develops in the form of triangular 
jets that become larger downstream along the channels, as it can be observed in the snapshots taken at different time instants included in Fig. 11(a). This operational regime is labelled as "jet-flow" due to the jet-like interface configuration, and it is a stable flow because the interface in the high-speed video maintains a stable behaviour in time and temperature oscillations have small magnitude.

For further smaller values of $G$ and larger $q$ (central area in plot in Fig. 10), the high-speed videos show a more spatially uniform transition between single phase and two-phase flow (the jets disappear), see Fig. 11(b). This results in a smoother change of the temperature from the inlet to the outlet of the micro-evaporator as it is apparent from the IR camera reading given in Fig. 8(a). This regime is called stable single phase flow followed by twophase flow and is a favorable flow regime because of its stability. Note from Fig. 11(b) that the single phase to two-phase transition occurs earlier at the center of the heated area and more downstream at the sides, due to the lateral spreading of heat toward the sides of the micro-evaporator. This motivates the use of a 3D heat conduction model in the data reduction rather than employing a more simple 1D model, as the latter cannot account for such a non-uniform heat flux at the test section footprint. At the lowest values of mass fluxes, the flow configuration becomes very unstable, as it can be observed in the two successive snapshots given in Fig. 11(c) in which the shape and location of the single phase to two-phase transition line along the test section changes substantially. The time-temperature plot reported in Fig. 9(b) gives a hint of the strong time-dependent nature of the flow under 
such conditions. The fluid instability is reflected by larger values of the standard deviation of the temperature measurements, up to $0.28^{\circ} \mathrm{C}$. Back flow toward the inlet plenum is also observed. As such, this regime is classified as unstable two-phase flow with back flow and it is an undesirable condition as it yields large spatial and temporal temperature gradients which may potentially prevent the correct functioning of the electronic device. Note that the area occupied by this unstable regime in the operational maps is wider for the test section without inlet restrictions, see Fig. 10(b). It extends at mass fluxes up to $1250 \mathrm{~kg} \mathrm{~m}^{-2} \mathrm{~s}^{-1}$, while when inlet restrictions are implemented instabilities are only observed for $G=750 \mathrm{~kg} \mathrm{~m}^{-2} \mathrm{~s}^{-1}$ and below. This once more demonstrates the beneficial effect of inlet restrictions on the stability of the flow. At the highest values of $q$ tested, a fully stable two-phase flow regime is encountered, although only for the test section with inlet restrictions. As can be seen in Fig. 11(d), transition to two-phase flow occurs near the inlet of the heated section and it remains stable in time. The two-phase flow covers most of heated area, and therefore this is the regime which gives the best heat transfer performance and, together with the stable single phase followed by two-phase flow operational condition, are the most stable and preferable operating regimes.

\subsection{Pressure drop}

The pressure drop represents a useful indicator of the necessary pumping power to push the fluid through the micro-pin fins evaporator. This information in contained in two parameters, the total pressure drop across the test section $\Delta p_{t o t}$, and the pressure drop across the pin fin array $\Delta p_{\text {fin }}$. For the test conditions analyzed in this work, the $\Delta p_{\text {fin }}$ for the two-phase flow 
boiling tests is about the $85-90 \%$ of the total pressure drop. As the $\Delta p_{\text {fin }}$ depends on the data reduction procedure, it is here preferred to present the the total pressure drop, $\Delta p_{t o t}$, measured via the differential pressure transducer. Furthermore, the total pressure drop is more indicative of the total power consumption of the system, which is a more relevant thermo-hydraulic parameter to characterize the micro-evaporator. Figure 12 displays the total pressure drop as a function of the outlet vapor quality (representative of the imposed heat flux) at different values of the mass flux, for the test section with and without inlet restrictions. The pressure drop increases with the mass flux as expected. It also grows with the outlet vapor quality, for two main reasons: larger $x_{\text {out }}$ means a higher heat flux and therefore a more substantial contribution of accelerational pressure drop; the higher accelerations also induce a larger drift velocity between vapor and liquid phases, thus increasing the interfacial shear stress and therefore the frictional pressure drop. The highest pressure drop measured in the presence of inlet restrictions is of about $170 \mathrm{kPa}\left(G=2000 \mathrm{~kg} \mathrm{~m}^{-2} \mathrm{~s}^{-1}\right.$ and $\left.q=48 \mathrm{~W} \mathrm{~cm}^{-2}\right)$. Note that, due to technical issues, the pressure drop test for the test section without inlet restrictions was limited to heat fluxes lower than $40 \mathrm{~W} \mathrm{~cm}^{-2}$ (see Fig. 10). Figure 13 presents a comparison of the pressure drops measured for the two test sections, and no appreciable differences in their magnitudes arise. These results further demonstrate the advantage of inlet restrictions, as they enhance the stability of the flow without any appreciable increase in the pumping power consumption of the system. 


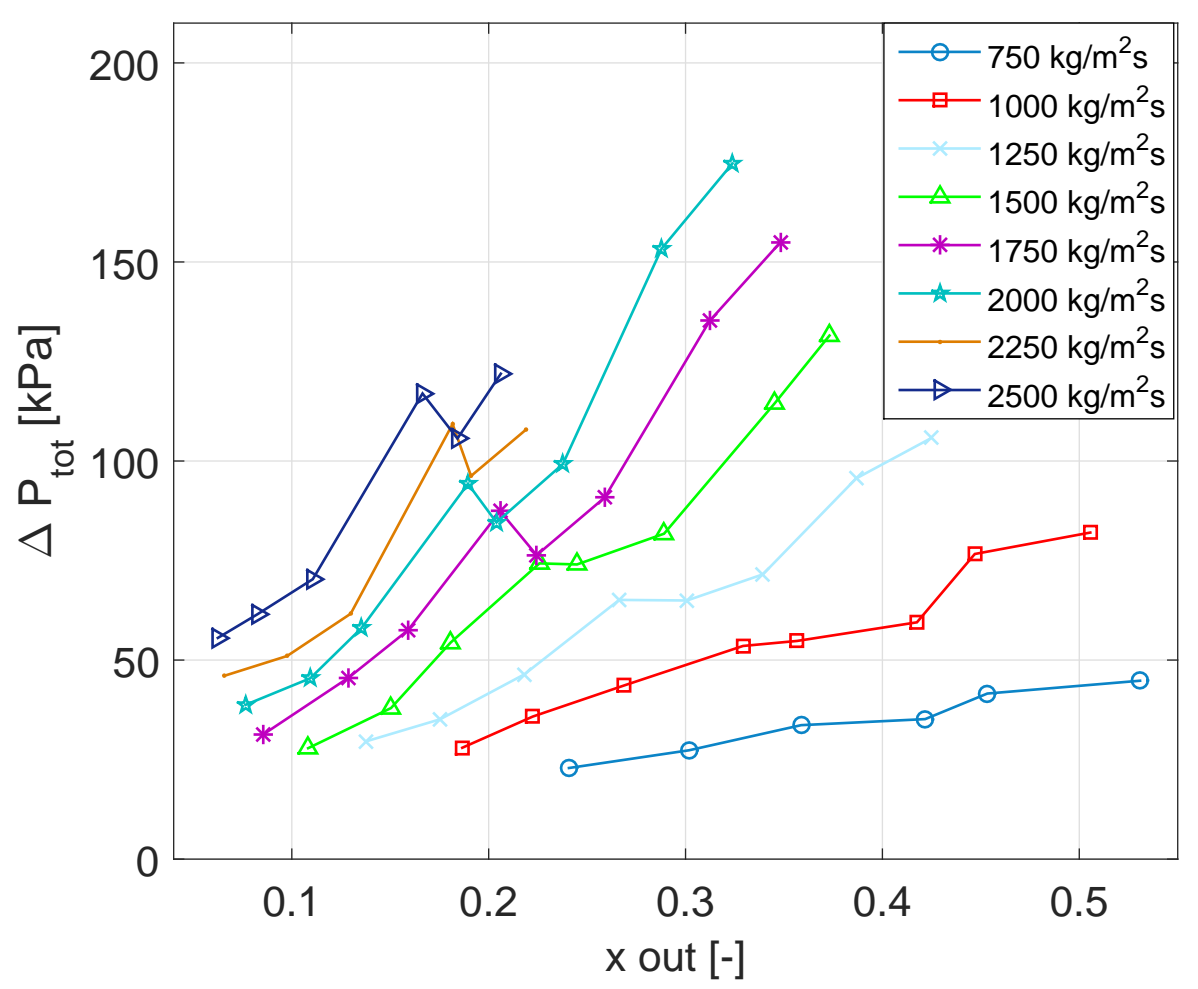

(a) Test section with inlet restrictions

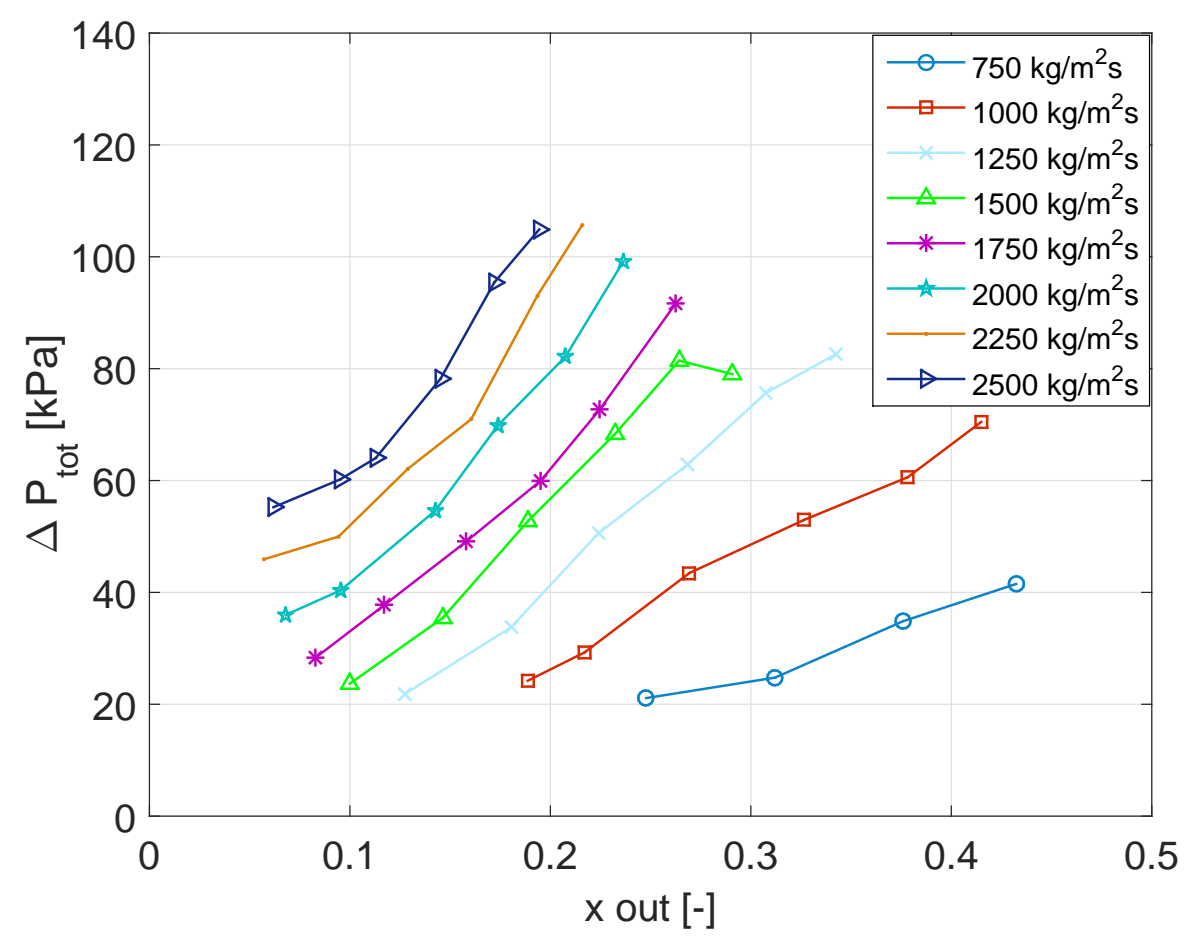

(b) Test section without inlet restrictions

Figure 12: Total measured pressure drop as function of the outlet vapor quality. 


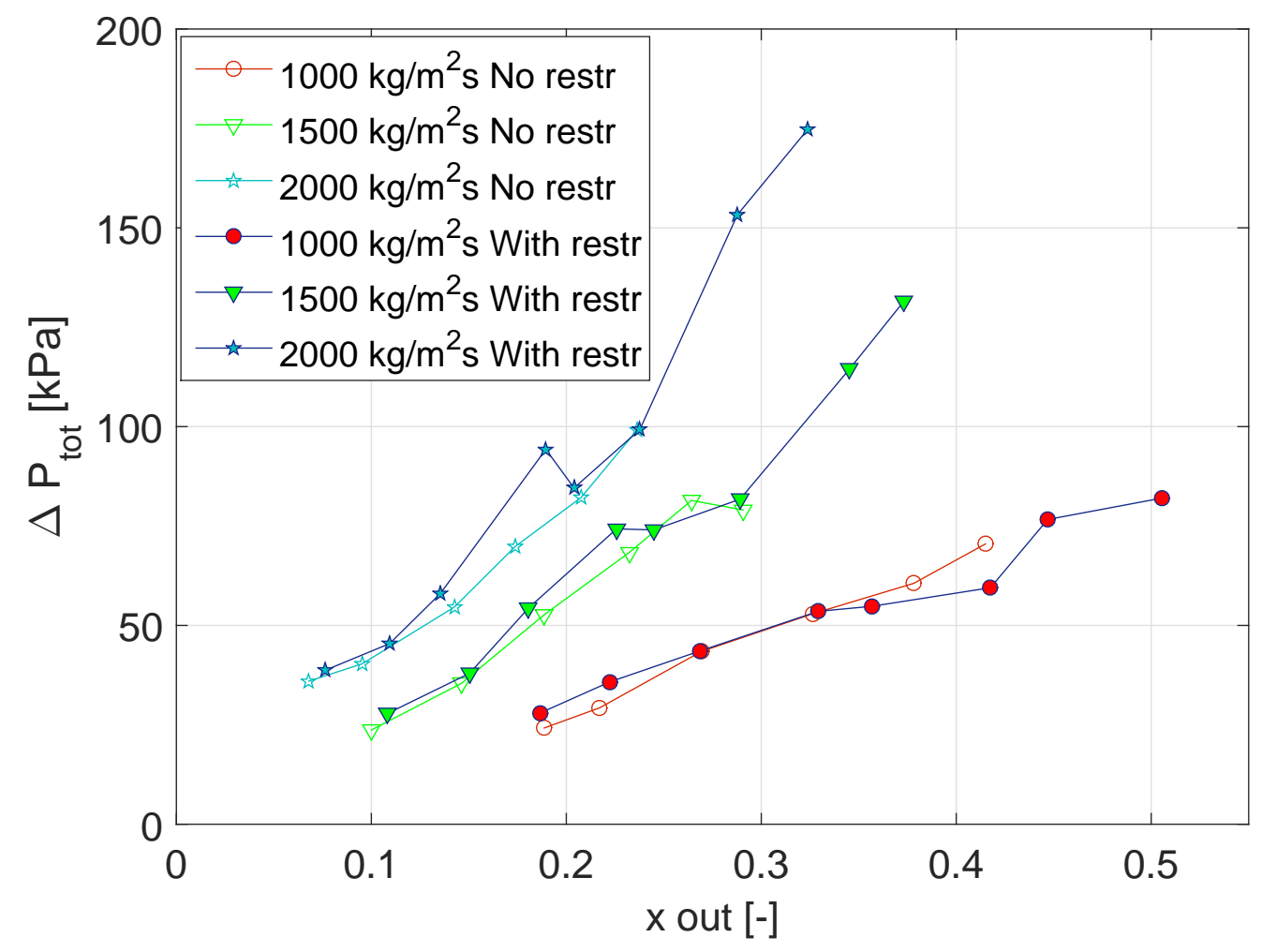

Figure 13: Comparison of the total pressure drop between the geometries with and without inlet restrictions.

Szczukiewicz et al. [34] performed flow boiling experiments in a multimicrochannel evaporator using the same test facility of the present study, for a geometry of the micro-evaporator comparable to the present one (67 parallel $100 \mu \mathrm{m}$ square microchannels), same fluid and similar test conditions. They measured a maximum pressure drop of about $125 \mathrm{kPa}\left(G=2102 \mathrm{~kg} \mathrm{~m}^{-2} \mathrm{~s}^{-1}\right.$ and $q=48.6 \mathrm{~W} \mathrm{~cm}^{-2}$ ), thus about $25 \%$ lower than those measured here. The higher pressure drop measured for the present study can be attributed to the disturbances created by the micro-pin fins geometry.

\subsection{Heat transfer coefficient}

The two-phase flow heat transfer results are illustrated in this section. The infrared camera provides a 2D map of the base temperature, from which the heat transfer coefficient $h_{w}$ is derived as explained in Section 3.2. This is 
then averaged along the widthwise direction to yield a widthwise "local" value of the heat transfer coefficient along the test section at each row of pixels, which will be the parameter presented in the figures below. As Szczukiewicz et al. [23] pointed out, the magnitude of the heat transfer coefficient changes dramatically according to the data reduction procedure. Deviations up to $83 \%$ were reported in [23] depending on the local pressure profile assumed to estimate the fluid temperature. Here, the use of a pressure drop prediction method (and not a linear pressure profile assumption) corrected to match the experimental data, and the implementation of a 3D heat conduction model accounting for lateral heat spreading and losses, are expected to be more representative of the actual two-phase flow thermal and fluid dynamics.

Figure 14 shows the heat transfer coefficient as a function of the local vapor quality for different values of the heat flux at a mass flux of $1500 \mathrm{~kg} \mathrm{~m}^{-2} \mathrm{~s}^{-1}$. The colors used for the plotted curves are indicative of their operational regimes as in Fig. 10(a). The fluid enters in the test section at subcooled conditions, which motivates the negative values of the vapor quality in Fig. 14. When $x<0$ the fluid is assumed to be at the single phase state, however the increasing trend of the heat transfer coefficient with heat flux suggests the presence of subcooled flow boiling, as a larger heat flux tends to generate more bubbles by wall nucleation. At positive values of the vapor quality, in general the heat transfer coefficient increases with the heat flux due to the effect of changes in the flow regimes, as it is explained below. A jet-flow regime is observed for $q=20 \mathrm{~W} \mathrm{~cm}^{-2}$ and $q=24 \mathrm{~W} \mathrm{~cm}^{-2}$, with two-phase flow only present toward the exit of the heated area. The 
heat transfer coefficient reduces monotonically with the vapor quality. This is consistent with the coalescing bubble flow pattern, where local dry-out nearby the tail of the very elongated bubbles causes a drop in the heat transfer coefficient. Since two-phase flow is present only at the exit, no other flow patterns develop. When the heat flux increases, the two-phase flow covers a wider area within the test section. For heat flux values between $28 \mathrm{~W} \mathrm{~cm}^{-2}$ and $40 \mathrm{~W} \mathrm{~cm}^{-2}$ (single phase followed by two-phase flow operational regime) the heat transfer curves present the typical U-shaped trend first emphasized by Ong and Thome [36] and Costa-Patry and Thome [37]. This is associated with the transition from coalescing bubble to annular flow regime (which identifies the minimum of the curve). The successive development of the annular flow enhances the heat transfer performance due to the evaporation and, therefore, thinning of the annular liquid film. At the largest heat fluxes tested, the two-phase flow covers almost entirely the heated area, thus resulting in very high heat transfer coefficients. The coalescing bubble regime is present only in a very limited portion of the flow area, as the local minimum of the U-shaped heat transfer coefficient curve is shifted toward very low values of the vapor quality (about 0.02), thus suggesting an earlier slug flow to annular flow transition.

In Fig. 15, the heat transfer coefficient versus vapor quality for different mass fluxes, at constant $q=20 \mathrm{~W} \mathrm{~cm}^{-2}$ is reported for the test section with inlet restrictions. The plot colors match the related operational regimes illustrated in Fig. 10. In the negative vapor quality region, the heat transfer coefficient increases with the mass flux. This trend is probably attributed to the 


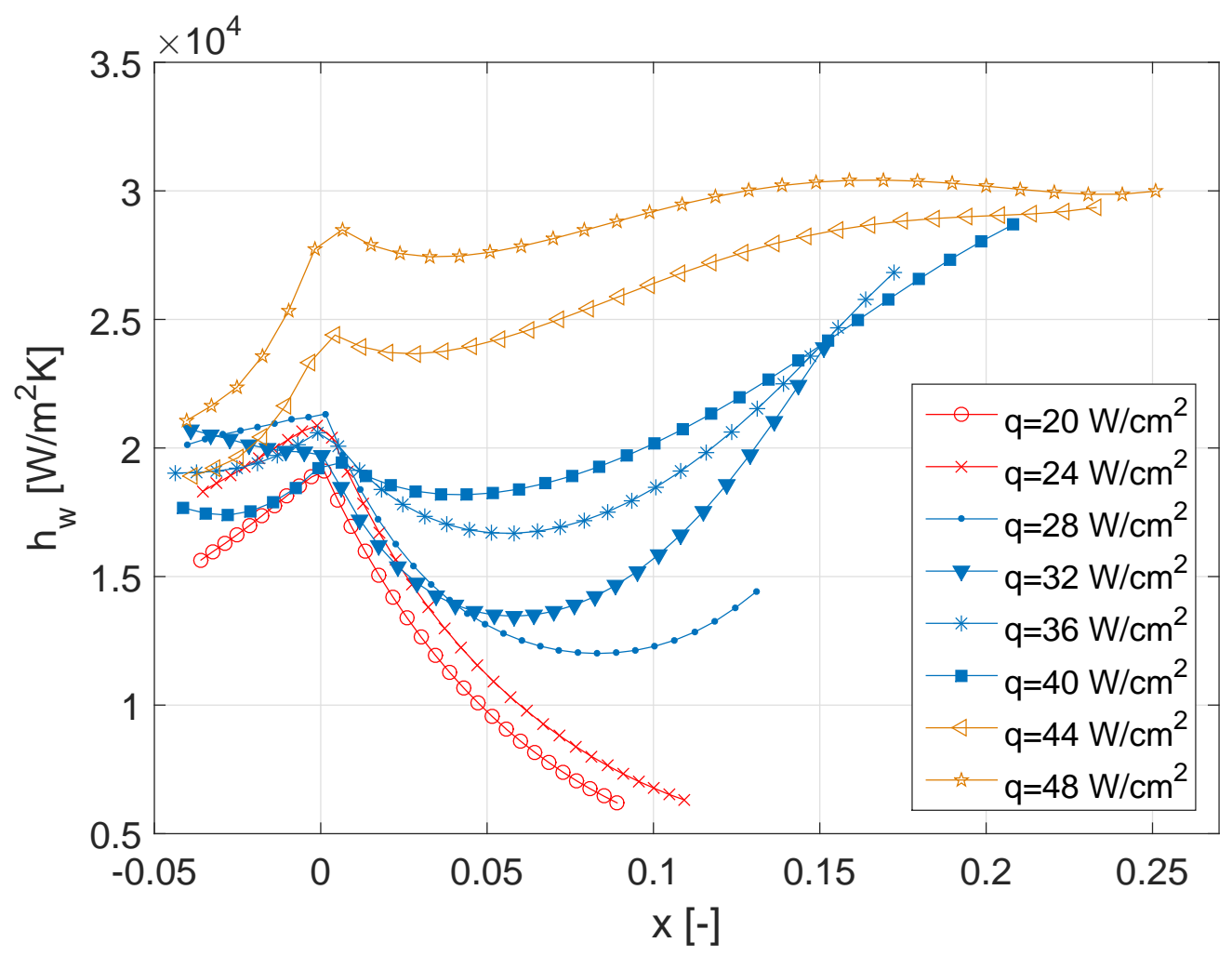

Figure 14: Local heat transfer coefficient as function of vapor quality for test section with inlet restrictions. Mass flux is $1500 \mathrm{~kg} \mathrm{~m}^{-2} \mathrm{~s}^{-1}$.

influence of the mass flux on the single phase developing flow, supplemented by addition nucleate boiling effects. In the two-phase flow region $(x>0)$ an opposite trend versus mass flux is observed, and this can be ascribed to a flow pattern dependence as it is explained below. For $G=750 \mathrm{~kg} \mathrm{~m}^{-2} \mathrm{~s}^{-1}$, the flow is unstable as indicated by the operational map in Fig. 10(a), the magnitude of the heat transfer coefficient is larger than the cases with higher mass flux (higher heat transfer coefficients for unstable flows were already reported in [38] and [23]), but this operational regime is undesirable. As the mass flux 


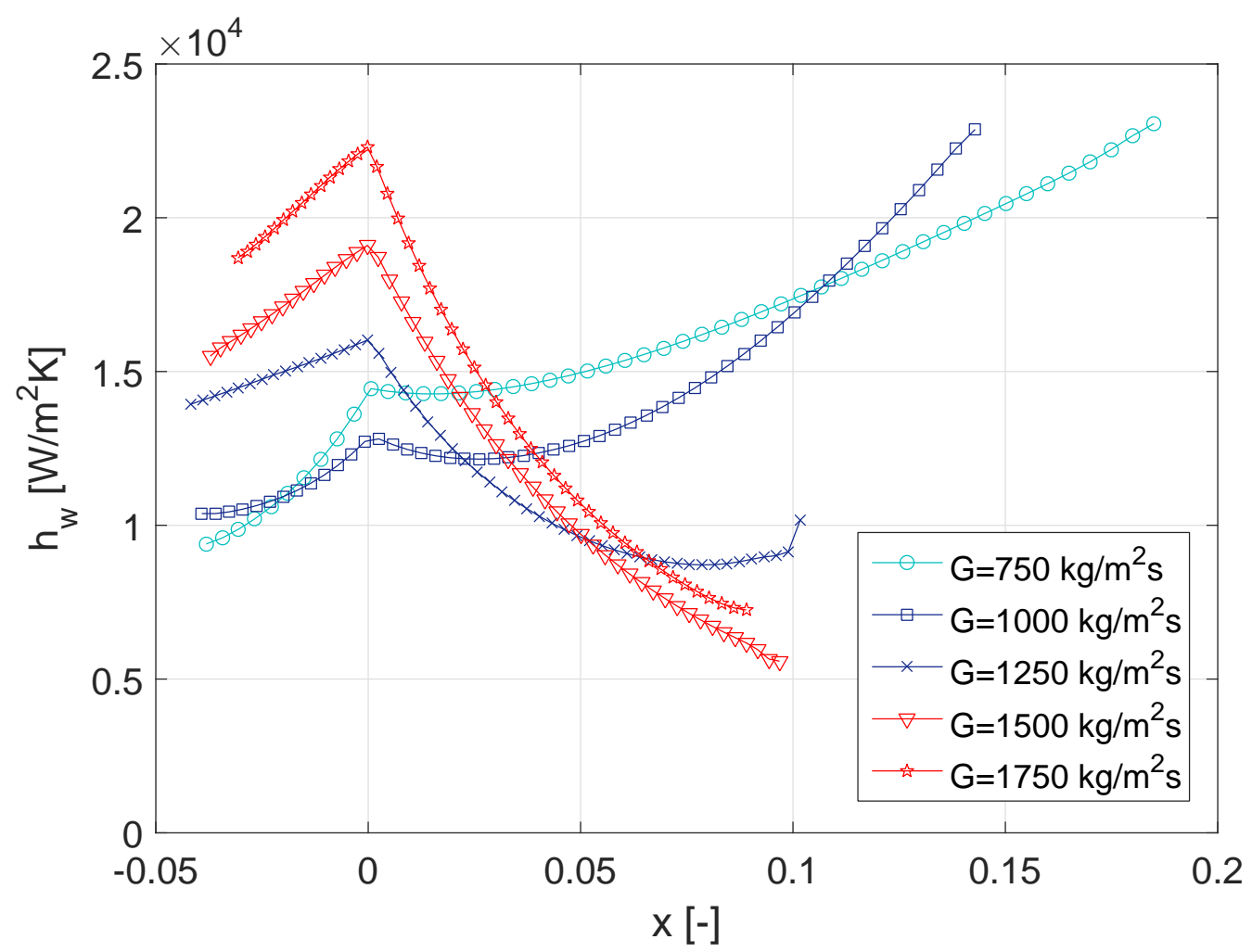

Figure 15: Local heat transfer coefficient as function of vapor quality for test section with inlet restrictions. Heat flux is $q=20 \mathrm{~W} \mathrm{~cm}^{-2}$.

is increased the flow becomes stable and the heat transfer decreases because, as the heat flux is maintained constant, the exit vapor quality drops such that the two-phase flow occupies a smaller region in the heated area and the annular flow regime cannot develop.

Figure 16 presents the effect of mass flux on the heat transfer performance at a larger value of heat flux, $q=44 \mathrm{~W} \mathrm{~cm}^{-2}$. As can be observed in the operational map of Fig. 10(a), all the presented cases correspond to the 


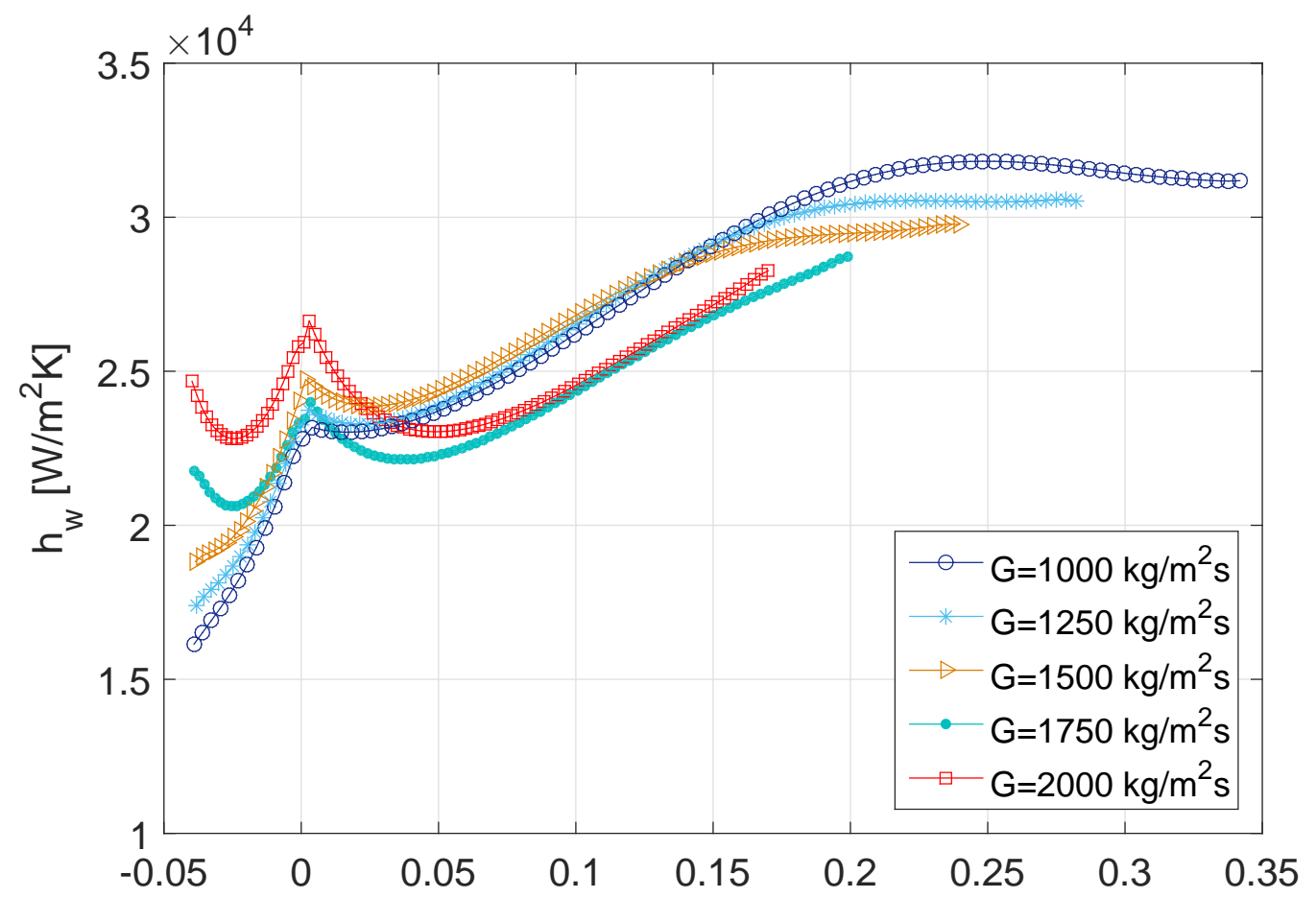

Figure 16: Local heat transfer coefficient as function of vapor quality for test section with inlet restrictions. Heat flux is $q=44 \mathrm{~W} \mathrm{~cm}^{-2}$.

fully stable two-phase flow regime. The heat transfer coefficient trends are substantially different than those observed in Fig. 15, because the larger heat flux value promotes the transition to annular flow such that all the plotted curves show a U-shape. The heat transfer coefficient in the two-phase flow region still falls when the mass flux is increased, although to a much smaller extent than the case with $q=20 \mathrm{~W} \mathrm{~cm}^{-2}$ illustrated in Fig. 15 .

Figure 17 provides a comparison of the heat transfer coefficient measured 
in the two test sections for selected operating conditions. In the sub-cooled

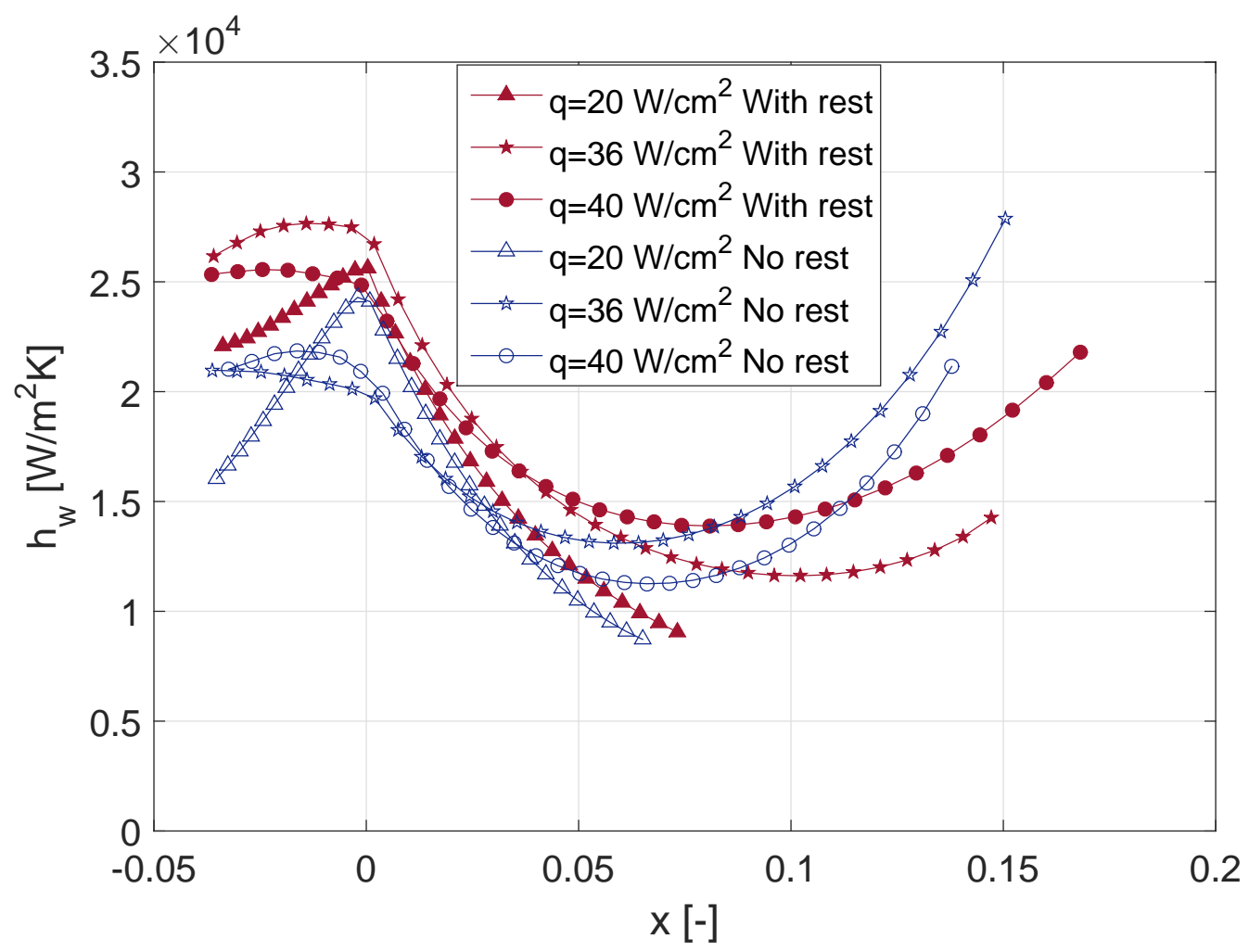

Figure 17: Comparison of local heat transfer coefficient as function of the vapor quality for the geometry with inlet restrictions and the geometry without. The test conditions showed are for a fixed mass flux equal to $2000 \mathrm{~kg} \mathrm{~m}^{-2} \mathrm{~s}^{-1}$.

flow boiling region, the geometry with inlet restrictions is characterized by larger values of the heat transfer coefficient which can be attributed to the enhanced single phase heat convection promoted by flow accelerations through the restrictions. In the saturated flow boiling region, when $q=20 \mathrm{~W} \mathrm{~cm}^{-2}$ the annular flow does not develop and only a descending trend is seen, with similar heat transfer magnitude for both the test sections. At $q=36 \mathrm{~W} \mathrm{~cm}^{-2}$ 
and $q=40 \mathrm{~W} \mathrm{~cm}^{-2}$, the two-phase flow covers a large part of the heated area, and the U-shaped trends of $h_{w}$ suggest that transition to annular flow occurs. The test section without inlet restrictions presents a steeper increase of $h_{w}$ at larger vapor qualities (annular flow region), however the minimum heat transfer coefficient value (coalescing bubble to annular flow transition) is shifted to smaller $x$ compared to the case with inlet restrictions. Therefore it seems that inlet restrictions tend to delay the formation of annular flow, which in turn explains the lower heat transfer performance at a given vapor quality value in the annular flow region compared to the results obtained for the test section without inlet restrictions.

The present heat transfer results have been compared to those obtained by Szczukiewicz et al. [9, 34]. With microchannels the flow boiling curves are all U-shaped and vary in a small range $\left(h_{w}=15-25 \mathrm{~kW} \mathrm{~m}^{-2} \mathrm{~K}^{-1}\right)$ when changing the test conditions. Indeed, mass flux is not an influential parameter and the heat flux has the only effect of shifting the curves vertically (see Fig. 9(a) in [34]). In the micro-pin fins flow configuration, the shapes of the flow boiling curves dramatically depend on the working conditions (mass flux and heat flux) and the variation in the heat transfer magnitude is larger $\left(h_{w}=5-30 \mathrm{~kW} \mathrm{~m}^{-2} \mathrm{~K}^{-1}\right)$. This suggests that the present geometry has a stronger impact on the heat transfer mechanisms, as the micro-pin fins are expected to disturb the flow to a larger extent than flat walls, also preventing the formation of a continuous thin liquid film which is characteristic of the annular flow regime. Therefore the present comparison does not allow one to conclude quantitatively whether flow boiling in a micro-pin fins evaporator 
gives a higher heat removal capability than multi-microchannels over a wide range of operating conditions.

\section{Conclusions}

Two-phase flow boiling in a micro-pin fins evaporator was investigated in the present work as a new potential cooling technology for high power density computer chips. A fine resolution infrared temperature measurement technique was coupled with high-speed flow visualization in order to analyze the interrelation between time-dependent fluid mechanics and heat transfer. The implementation of a data reduction procedure based on a pressure drop prediction method (and not on a linear pressure profile assumption) to reconstruct the local fluid temperature along the test section, and on a 3D heat conduction model accounting for lateral heat spreading and losses to derive the channel wall temperature, is expected to be more representative of the actual two-phase flow thermal and fluid dynamics when compared to existing studies. Operational maps, pressure drop, and heat transfer performance are studied for a wide range of operating conditions. The major outcomes of this work can be drawn as follows:

- Using flow visualization, four different two-phase flow operational regimes are identified: jet-flow, single phase followed by two-phase flow, unstable two-phase flow and fully stable two-phase flow. Two of these are found to be fully stable and favorable to achieve large values of the heat transfer coefficient.

- The presence of inlet restrictions at the entrance of the heated area extends the map of stable operational regimes toward lower values of 
the mass flux, down to $G=1000 \mathrm{~kg} \mathrm{~m}^{-2} \mathrm{~s}^{-1}$ compared to the operational lower limit of $G=1500 \mathrm{~kg} \mathrm{~m}^{-2} \mathrm{~s}^{-1}$ detected without restrictions.

- The pressure drop increases with mass flux and heat flux, and inlet restrictions do not increase the pressure drop in a noticeable way when compared to the test section without. This further demonstrates the beneficial effect of inlet restrictions, as they enhance the stability of the flow without any appreciable increase in the pumping power consumption of the system. The highest total pressure drop, measured at a mass flux of $2000 \mathrm{~kg} \mathrm{~m}^{-2} \mathrm{~s}^{-1}$ and heat flux of $48 \mathrm{~W} \mathrm{~cm}^{-2}$, is about $170 \mathrm{kPa}$.

- Heat transfer coefficient trends and magnitudes show a substantial dependence on vapor quality, mass flux and heat flux, which can be attributed to flow pattern effects. At low heat flux or high mass flux, only a descending trend when increasing vapor quality is seen. At higher values of the heat flux or lower values of mass flux, the U-shaped trend versus vapor quality typically observed in multi-microchannel evaporators is found, thus suggesting that transition from slug to annular flow occurs. In general, the heat transfer performance improves when increasing heat flux, while it tends to reduce when mass flux is raised, depending on the flow regime established along the test section.

- The significant influence of mass flux and heat flux on the heat transfer performance of the micro-evaporator suggests that the pin fin geometry has a much stronger impact on the two-phase flow patterns development than parallel microchannels, where such a dependence is less pro- 
nounced. In particular, micro-pin fins delay the transition to annular flow, as they prevent the formation of the continuous thin liquid film on the channel walls which is characteristic of the annular flow regime.

\section{Acknowledgements}

M. Magnini is supported by the Swiss National Science Foundation (SNSF) under Contract No. 200020-156181. 


\section{Nomenclature}

\begin{tabular}{|c|c|}
\hline$A$ & area \\
\hline$B$ & heated area width \\
\hline$c_{p}$ & specific heat \\
\hline$D_{h}$ & channel hydraulic diameter \\
\hline$e_{\text {restr }}$ & inlet restrictions expansion ratio \\
\hline$f$ & Fanning friction factor \\
\hline$G$ & mass flux \\
\hline$H$ & height \\
\hline$h$ & heat transfer coefficient \\
\hline$k$ & thermal conductivity \\
\hline$i$ & enthalpy \\
\hline$i_{L V}$ & vaporization latent heat \\
\hline$I$ & current \\
\hline$L$ & heated area length \\
\hline $\mathrm{Nu}$ & Nusselt number, $h D_{h} / k$ \\
\hline$\dot{m}$ & mass flux \\
\hline$N_{c h}$ & number of channels between the pin fin lines \\
\hline$N_{\text {fin }}$ & total number of micro-pin fins \\
\hline$p$ & pressure \\
\hline$P$ & perimeter of the cross section of the channel \\
\hline
\end{tabular}




\begin{tabular}{l|l}
$q$ & heat flux \\
$Q_{e l}$ & electrical power input \\
$Q_{\text {losses }}$ & heat losses \\
$\operatorname{Re}$ & Reynolds number, $G D_{h} / \mu$ \\
$T$ & temperature \\
$V$ & voltage drop across the heater \\
$W$ & width \\
$x$ & vapor quality \\
$y, z$ & widthwise and streamwise coordinates
\end{tabular}

\section{Greek Letters}

\begin{tabular}{l|l}
$\eta_{f i n}$ & fin efficiency \\
$\mu$ & dynamic viscosity \\
$\rho$ & density
\end{tabular}




\begin{tabular}{l|l} 
Subscripts & \\
$a$ & accelerational \\
amb & ambient \\
base & base \\
ch & channel \\
cont & contraction \\
end & end of the test section \\
exp & expansion \\
$f$ & frictional \\
$f i n$ & micro-pin fins \\
$f l$ & fluid \\
$f t p$ & footprint \\
in & inlet \\
$l$ & liquid \\
$l o c$ & local \\
out & outlet \\
sat & saturation \\
sil & silicon \\
$v$ & two-phase \\
$w$ & vapor \\
\hline wall
\end{tabular}

\section{References}

[1] R. Fillion, Advanced packaging technology for leading edge microelectronics and flexible electronics, Cornell University MSE 542 lecture-GE 
Global Research (2011).

[2] M. M. Sabry, A. Sridhar, D. Atienza, Y. Temiz, Y. Leblebici, S. Szczukiewicz, N. Borhani, J. R. Thome, T. Brunschwiler, B. Michel, Towards thermally-aware design of 3D MPSoCs with inter-tier cooling, Design, Automation and Test in Europe Conference \& Exhibition (2011).

[3] J. B. Marcinichen, J. A. Olivier, J. R. Thome, Reasons to use two-phase refrigerant cooling, Electr. Cool 17 (2011) 22-27.

[4] S. G. Kandlikar, Fundamental issues related to flow boiling in minichannels and microchannels, Exp. Th. Fluid Science 26 (2002) 389-407.

[5] G. Hetsroni, D. Klein, A. Mosyak, Z. Segal, E. Pogrebnyak, Convective boiling in parallel microchannels, Microscale Thermophysical Engineering 8 (2004) 403-421.

[6] W. Qu, I. Mudawar, Flow boiling heat transfer in two-phase microchannel heat sinks -I. experimental investigation and assessment of correlation methods, Int. J. Heat Mass Transfer 46 (2003) 2755-2771.

[7] B. Agostini, M. Fabbri, E. Park, L. Wojtan, J. R. Thome, B. Michel, State of the art of high heat flux cooling technologies, Heat Transfer Engineering 28(4) (2003) 258-281.

[8] T. Harirchian, S. V. Garimella, Microchannel size effects on local flow boiling heat transfer to a dielectric fluid, Int. J. Heat Mass Transfer 51 (2008) 3724-3735. 
[9] S. Szczukiewicz, N. Borhani, J. R. Thome, Two-phase heat transfer and high-speed visualization of refrigerant flows in $100 \times 100 \mu \mathrm{m}$ silicon multi-microchannels, Int. J. Refrigeration 36 (2013) 402-413.

[10] H. Huang, N. Borhani, J. R. Thome, Experimental investigation on flow boiling pressure drop and heat transfer of R1233zd(E) in a multimicrochannel evaporator, Int. J. Heat Mass Transfer 98 (2016) 596-610.

[11] A. Renfer, M. K. Tiwari, R. Tiwari, F. Alfieri, B. Michel, D. Poulikakos, Microvortex-enhanced heat transfer in 3D-integrated liquid cooling of electronic chip stacks, Int. J. Heat Mass Transfer 65 (2013) 33-43.

[12] T. Brunschwiler, B. Michel, H. Rothuizen, U. Kloter, B. Wunderle, H. Oppermann, H. Reichl, Interlayer cooling potential in vertically integrated packages, Microsyst. Technol. 15 (2009) 57-74.

[13] W. Qu, A. Siu-Ho, Liquid single phase flow in an array of micro-pin-fins part I: Heat transfer characteristics, ASME J. Heat Transfer 130 (2008) $122402-1-11$.

[14] S. Krishnamurthy, Y. Peles, Flow boiling of water in a circular staggered micro-pin fin heat sink, Int. J. Heat Mass Transfer 51 (2008) 1349-1364.

[15] J. Mita, W. Qu, Pressure drop of water flow across a micro-pin-fin array part 1: Isothermal liquid single-phase flow, ASME J. Heat Transfer 89 (2015) 1073-1082.

[16] J. Mita, W. Qu, Pressure drop of water flow across a micro-pin-fin array part 2: Adiabatic liquid-vapor two-phase flow, ASME J. Heat Transfer 89 (2015) 1007-1015. 
[17] A. Kosar, Y. Peles, Convective flow of refrigerant (R-123) across a bank of micro pin fins, Int. J. Heat Mass Transfer 49 (2006) 3142-3155.

[18] A. Kosar, Y. Peles, Boiling heat transfer in a hydrofoil-based micro pin fin heat sink, Int. J. Heat Mass Transfer 50 (2007) 1018-1034.

[19] D. Chisholm, A. D. K. Laird, Two-phase flow in rough tubes, Trans. ASME 80 (1958) 276.

[20] S. Krishnamurthy, Y. Peles, Flow boiling heat transfer on micro pin fins entrenched in a microchannel, ASME J. Heat Transfer 132 (2010) 1-7.

[21] R. W. Lockhart, R. C. Martinelli, Proposed correlation of data for isothermal two-phase, two-component flow in pipes, Chemical Engineering Progress 45 (1949) 39-48.

[22] S. Isaacs, Y. Kim, A. J. McNamara, Y. Joshi, Y. Zhang, M. S. Bakir, Two-phase flow and heat transfer in pin-fin enhanced microgaps, Thermal and Thermomechanical Phenomena in Electronic Systems (ITherm), 13th IEEE Intersociety Conference (2012).

[23] S. Szczukiewicz, M. Magnini, J. R. Thome, Proposed models, ongoing experiments, and latest numerical simulations of microchannel twophase flow boiling, Int. J. Multiphase Flow 59 (2014) 84-101.

[24] S. Szczukiewicz, Thermal and visual operational characteristics of multimicrochannel evaporators using refrigerants, PhD thesis, Ecole Polytechnique Fédérale de Lausanne (2012). 
[25] H. Wu, P. Cheng, Visualization and measurement of periodic boiling in silicon microchannels, Int J. Heat Mass Transfer 46 (2003) 2603-2614.

[26] J. E. Park, J. R. Thome, B. Michael, Effect of inlet orifices on saturated $\mathrm{CHF}$ and flow visualization in multi-microchannel heat sinks, In: 25th IEEE SEMI-THERM Symposium (2009).

[27] S. J. Kline, F. A. McClintock, Describing uncertainties in single-sample experiments, Mech. Eng. 75 (1953) 3-8.

[28] P. Lee, V. Garimella, Saturated flow boiling heat transfer and pressure drop in silicon microchannel arrays, Int. J. Heat Mass Transfer 51 (2008) 789-806.

[29] R. Prasher, J.-Y. Chang, A. Myers, D. Chau, D. He, Nusselt number and friction factor of staggered arrays of low aspect ratio micropin-fins under cross flow for water as fluid, ASME J. Heat Transfer 129 (2007) 141-153.

[30] A. Renfer, M. Tiwari, B. Michel, D. B. Murray, D. Poulikakos, T. Brunschwiler, Experimental investigation into vortex structure and pressure drop across microcavities in 3D integrated electronics, Exp. Fluids 51 (2011) 731-741.

[31] H. R. Shanks, P. H. Sidles, P. D. Maycock, G. C. Danielson, Thermal conductivity of silicon from 300 to 1400 K, Phys. Rev. 130(5) (1963) 1743-1748.

[32] A. Zukauskas, R. Ulinskas, Heat transfer from tubes in cross flow, Advances in Heat Transfer, Academic, New York 8 (1972). 
[33] E. Costa-Patry, E. Olivier, B. Nichita, B. A. Michael, J. R. Thome, Two-phase flow of refrigerants in $85 \mu \mathrm{m}$-wide multi-microchannels: Part I-Pressure drop, Int. J. Heat Fluid Flow 32 (2011) 451-463.

[34] S. Szczukiewicz, N. Borhani, J. R. Thome, Fine-resolution twophase heat transfer coefficient measurements of refrigerants in multimicrochannel evaporators, Int. J. Heat Mass Transfer 67 (2013) 913929.

[35] A. Cicchitti, C. Lombardi, M. Silvestri, G. Soldaini, R. Zavattarelli, Two-phase cooling experiments - pressure drop, heat transfer and burnout measurements, Energia Nucleare 7 (1960) 407-425.

[36] C. L. Ong, J. R. Thome, Macro-to-microchannel transition in two-phase flow: Part 2 - flow boiling heat transfer and critical heat flux, Exp. Th. Fluid Science 35 (2011) 873-886.

[37] E. Costa-Patry, J. R. Thome, Flow pattern-based flow boiling heat transfer model for microchannels, Int. J. Refrigeration 36 (2013) 414420.

[38] L. Consolini, J. R. Thome, Micro-channel flow boiling heat transfer of R-134a, R-236fa, and R-245fa, Microfluid Nanofluid 6 (2009) 731-746. 